\title{
HVMANITAS
}

\section{Responsabilidad y ambigüedad de Helena en la épica homérica}

\section{Autor(es): $\quad$ Gómez Seijo, Francisca}

Publicado por: Imprensa da Universidade de Coimbra

URL persistente:

URI:http://hdl.handle.net/10316.2/41848

DOI:

DOI:https://doi.org/10.14195/2183-1718_69_1

Accessed : $\quad$ 26-Apr-2023 07:49:27

A navegação consulta e descarregamento dos títulos inseridos nas Bibliotecas Digitais UC Digitalis, UC Pombalina e UC Impactum, pressupõem a aceitação plena e sem reservas dos Termos e Condições de Uso destas Bibliotecas Digitais, disponíveis em https://digitalis.uc.pt/pt-pt/termos.

Conforme exposto nos referidos Termos e Condições de Uso, o descarregamento de títulos de acesso restrito requer uma licença válida de autorização devendo o utilizador aceder ao(s) documento(s) a partir de um endereço de IP da instituição detentora da supramencionada licença.

Ao utilizador é apenas permitido o descarregamento para uso pessoal, pelo que o emprego do(s) título(s) descarregado(s) para outro fim, designadamente comercial, carece de autorização do respetivo autor ou editor da obra.

Na medida em que todas as obras da UC Digitalis se encontram protegidas pelo Código do Direito de Autor e Direitos Conexos e demais legislação aplicável, toda a cópia, parcial ou total, deste documento, nos casos em que é legalmente admitida, deverá conter ou fazer-se acompanhar por este aviso. 


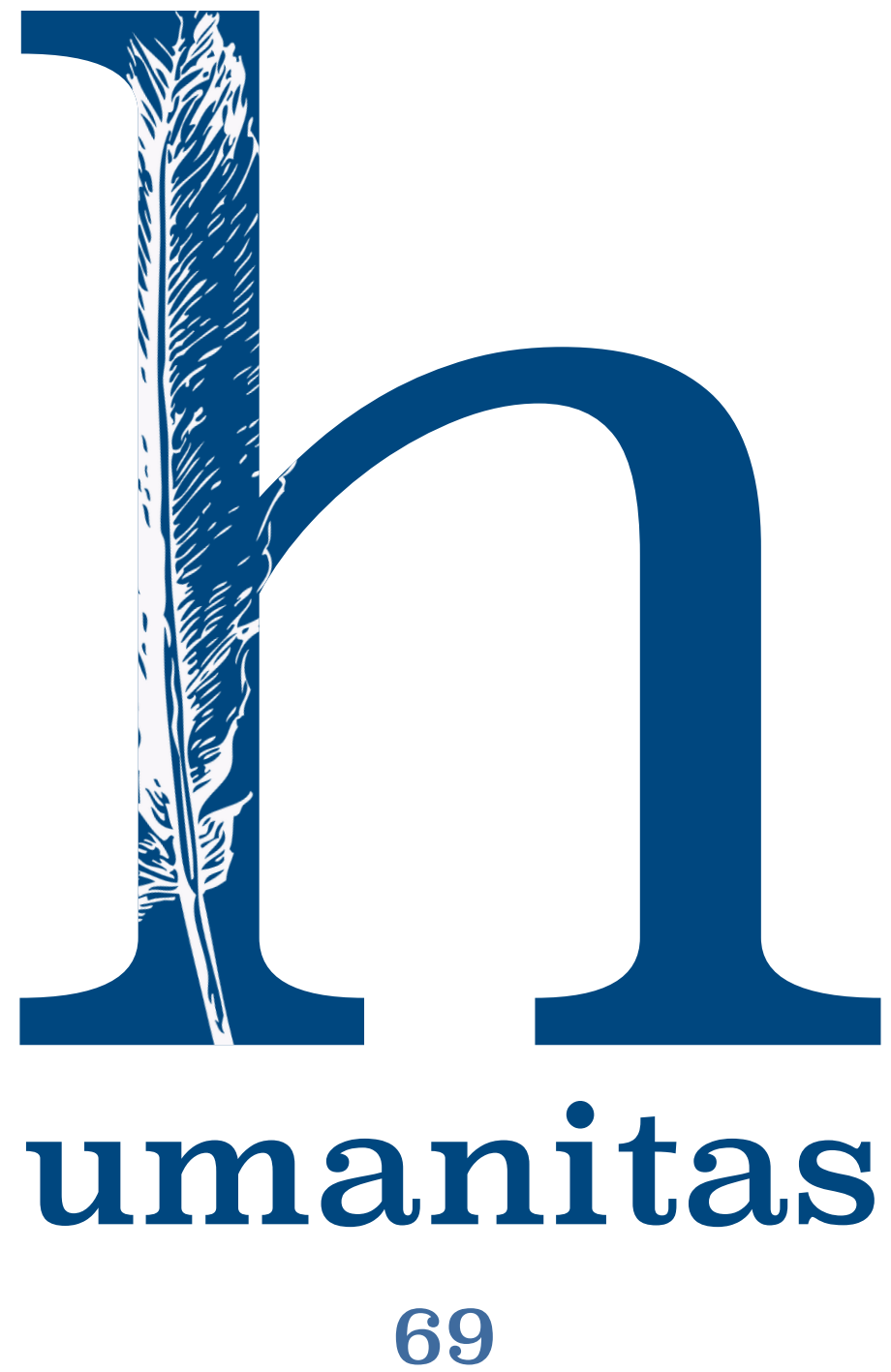

Imprensa da Universidade de Coimbra

Coimbra University Press 


\title{
ReSPONSABILIDAd Y AMBIgÜEdAd DE HeLENA EN LA ÉPICA HOMÉRICA
}

\author{
RESPONSIBILITY AND AMBIGUITY OF HELEN \\ IN HOMERIC EPIC
}

\author{
Francisca Gómez SeiJo \\ Instituto de Enseñanza Secundaria Álvaro Cunqueiro \\ f.gomez.seijo@hotmail.com
}

Artigo recebido a 14-06-2016 e aprovado a 02-02-2017

\section{Resumen}

En este artículo la autora trata de señalar la conveniencia de revisar dos cuestiones vinculadas de manera recurrente a la caracterización de Helena en la épica homérica: su responsabilidad en la guerra de Troya y su ambigüedad. Diversos estudios críticos se centran en tales cuestiones, pero desde enfoques igualmente diversos. El presente trabajo intenta conciliar sus conclusiones y, a la vez, aportar una visión personal sobre el papel de Helena en la Ilíada y la Odisea.

Palabras clave: épica homérica, Helena, responsabilidad, ambigüedad, caracterización

\section{Abstract}

In this paper the author tries to point out the convenience of addressing two issues often discussed around the characterization of Helen in Homeric epics: her responsibility in the Trojan War and her ambiguity. Several critical studies focus on such issues, but from equally diverse approaches. This paper attempts to reconcile their proposals findings and, at the same time, provide a personal view on the role of Helen in the Iliad and the Odyssey.

Keywords: Homeric epic, Helen, responsibility, ambiguity, characterization 
En el presente trabajo me propongo revisar las dos cuestiones que aparecen inseparablemente unidas en los estudios dedicados a la caracterización de Helena, no solo en la épica homérica, sino también en la lírica y en el drama, a saber: su responsabilidad en la guerra de Troya y su ambigüedad. Con respecto a la primera cuestión analizaré los datos ofrecidos por los diferentes personajes de la Ilíada, así como por el propio poeta épico en calidad de narrador omnisciente, y también la contribución de algunos trabajos orientados a dilucidar este tema de la responsabilidad de Helena. En lo tocante a su ambigüedad, procuraré demostrar que tal rasgo es producto, a menudo, de una lectura de la Ilíada y la Odisea en clave psicológica, lectura que es especialmente desaconsejable en un poema épico cuya autoría es incierta y que ha tomado forma definitiva tras una larga tradición oral de varios siglos. Komornicka conecta la falta de consenso entre la crítica con respecto a la actitud y el rol de Helena en el conflicto entre griegos y troyanos con nuestra ignorancia sobre si "las diversas imágenes de Helena son fruto de la invención de Homero o si han sido inspiradas —al menos en parte- por una tradición anterior adoptada por el poeta"1. La autora llega a la conclusión de que "la incoherencia de la imagen de Helena - tal como la constatamos en los poemas épicos- es debida ante todo a la naturaleza del mito, que depende en buena medida de variantes en su evolución y cuyos límites están borrosos y son oscilantes"2. Por otra parte, cuando se habla de la ambigüedad de la Helena épica, opino que a menudo proyectamos nuestras expectativas modernas de coherencia sobre su caracterización y este hecho le confiere una opacidad gratuita a la comprensión del personaje y de su papel en el poema. La ambigüedad se convierte, además, en punto de partida y de llegada, así como en el rasgo esencial que, supuestamente, formaba parte del proyecto original del poeta épico. Dedicaré las siguientes páginas al estudio de ambas epopeyas, empezando por la Ilíada .

\title{
Ilíada
}

Las referencias a Helena como la mujer por cuya causa tuvo lugar la guerra de Troya (Il. 1.159-60; 3.126-8, 156-7, 4.173-4; 6.344-58; 7.350-1;

\author{
Komornicka 1991: 9. \\ Komornicka 1991: 13-4. \\ Las ediciones utilizadas para los textos griegos son las oxonienses de D. B. Monro
} y T.W. Allen para la Ilíada (Oxford, 1903) y de T. W. Allen para la Odisea (Oxford, 1908). Las traducciones de dichos textos son mías. 
$9.339 ; 19.325 ; 22.114-6 ; 24.762-74)$, así como los insultos y las duras imprecaciones que profiere contra sí misma, deben contextualizarse, por tanto, en el marco de un extenso poema épico que no la señala como responsable única, ni directa ni voluntaria, de la contienda. La Ilíada presenta las palabras y las acciones de los personajes desde un doble plano - humano y divino- que relativiza la responsabilidad de Helena en la guerra y la hace, en todo caso, copartícipe de ella. Por otra parte, el componente patético de la execración dirigida contra sí misma contribuye a la caracterización del personaje y a los intereses de un tipo de poesía que ensalza la gloria guerrera del héroe tanto como deplora su muerte y el desgarrado dolor que produce en ambos bandos.

Examinada en su totalidad, la Ilíada nos presenta la guerra de Troya como la consecuencia de una suma de responsabilidades irreductibles a las acciones de una sola mujer. Héctor (Il. 3.85-91) comunica a troyanos y aqueos la decisión de Alejandro, "por cuya causa se desencadenó el

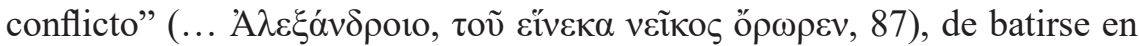
duelo singular con Menelao "por Helena y por todas las riquezas" ( $\dot{\alpha} \mu \varphi$ '

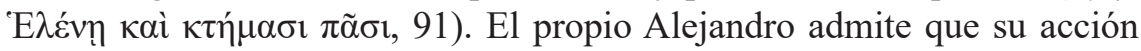
fue la de raptar a Helena (Il. 3.444-5). También Héctor (Il. 6.325-9) le hace reproches a su hermano: "por tu causa el griterío y el combate arden

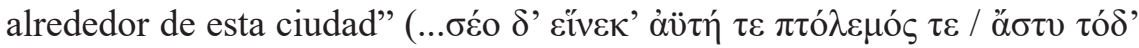
$\grave{\alpha} \mu \varphi 1 \delta \varepsilon \delta \delta \eta \varepsilon^{* . . ., 328-9)}$ y le dice (Il. 6.517-25) que le produce gran aflicción escuchar los insultos que le dedican los troyanos, "que soportan muchas

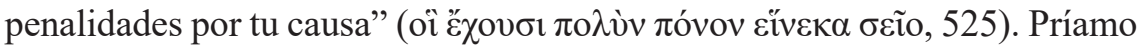
(Il. 7.365-74) se refiere a su propio hijo como aquel "por cuya causa se

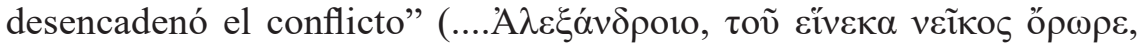
374). Incluso el poeta afirma (Il. 24.25-30) que Hera, Poseidón y Atenea persisten en su odio contra los troyanos "por culpa de la átē de Alejandro"

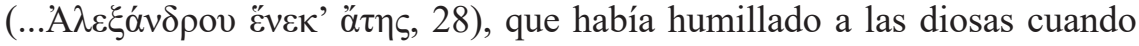

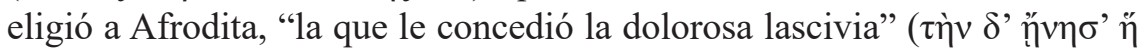

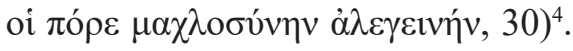

Además de los versos en los que se señala la responsabilidad de Paris, se pueden citar otros en los que recae sobre los dioses: Príamo exonera a Helena (Il. 3.164-5): "Para mí tú no eres culpable de nada; los causantes

4 Estos versos iniciales del canto 24 que hacen referencia al episodio del juicio de Paris ponen de manifiesto hasta qué punto el poeta-narrador suponía que eran conocidas por el auditorio historias anteriores que inciden sobre la estructura de la trama de la Ilíada (historias tales como la de las bodas de Tetis y Peleo, que engendran a Aquiles y evitan el peligro de un hijo nacido de la unión de Tetis con Zeus). 
son los dioses, que trajeron esta guerra, fuente de lágrimas, contra los

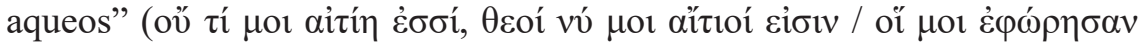
$\pi \delta ́ \lambda \varepsilon \mu \rho v \pi \circ \lambda v ́ \delta \alpha \kappa \rho v v$ 'A $\left.A \alpha \imath \tilde{\omega} v^{*}\right)$. La propia Helena, tras referirse primero a sí misma como 'perra' (Il. 6.344), afirma pocos versos después (349) que los dioses han sido los responsables de las desgracias sucedidas. Por último, el poema señala a una divinidad en concreto como responsable de la guerra: se trata de Afrodita, a la que Helena se enfrenta en el canto 3, haciéndole reproches por haberla destinado a ser el regalo otorgado a Paris, un favorito de la diosa.

Dado que es posible detectar tres responsables directos y activos de la guerra - Paris, los dioses en general y Afrodita en particular- ¿cómo conjugar, entonces, las referencias a la inocencia de Helena con los versos en los que se afirma que muchos héroes murieron por su causa? En opinión de Bettini y Brillante, "tales afirmaciones no pretenden resaltar la responsabilidad personal de la mujer, sino poner en primer plano el papel que ella desempeña en el conflicto. Por el solo hecho de encontrarse en Troya y verse disputada por las dos partes, Helena constituye una desgracia para Príamo y para los troyanos. Ella representa de manera emblemática, más allá de su voluntad, la causa de la guerra y, por tanto, también la de los duelos y las desgracias que se abaten sobre griegos y troyanos"s. Los autores apoyan su afirmación con dos ejemplos: recordando las batallas libradas contra las ciudades de la Tróade, Aquiles afirma que había luchado con los hombres "a causa

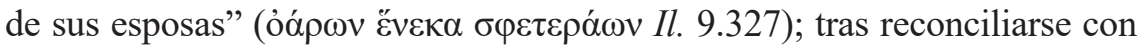
Agamenón a causa de la disputa por Briseida (Il.19.56-62), el héroe expresa el deseo de que la esclava hubiera muerto el día en el que conquistó Lirneso, la ciudad de la que ella procedía. De esta manera no habrían perdido la vida

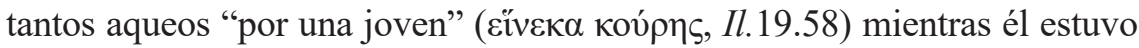
encolerizado con Agamenón. Helena se convierte así, al igual que Briseida, en la causa de una guerra que no quería y que no puede detener.

El hecho de que la responsabilidad aparezca repartida en la Ilíada y que Helena no sea señalada como la única responsable de tantas desgracias,

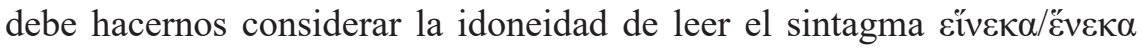
'E $\lambda \dot{\varepsilon} v \eta \varsigma$ dentro de un contexto en el que la atribución de la responsabilidad

5 Bettini y Brillante 2008: 72. A estas observaciones conviene añadir, no obstante, que sin esta guerra acaecida por causa de Helena, el héroe Aquiles no podría demostrar su

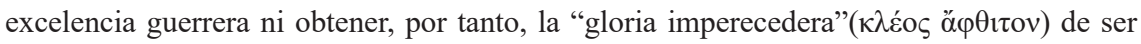
recordado por las generaciones futuras a través de aedos y rapsodas. 
no es unilateral. En su estudio sobre la causa con referentes humanos en los poemas homéricos, Conti Jiménez distingue tres subtipos de causa en su uso como actantes de los verbos de dolor y de los verbos de cólera ${ }^{6}$ :

1) Causante involuntario: persona que desencadena el estado de cosas descrito en la oración por medio de una situación que escapa a su control. Este 'causante involuntario' aparece expresado mediante el genitivo sin

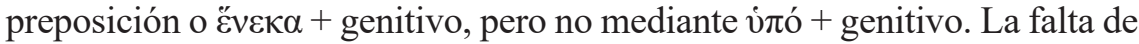
responsabilidad del causante involuntario sobre la situación que desencadena se manifiesta en numerosos ejemplos en los que el genitivo sin preposición

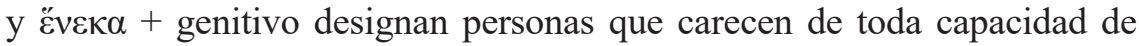
acción. De hecho, en muchas ocasiones son difuntos quienes provocan el dolor o la cólera de sus allegados o amigos (Il. 1.93-4; 1.56).

2) Responsable sin intencionalidad: persona que desencadena el estado de cosas con una acción controlada, pero no intencionada. Como en el subtipo anterior, el 'responsable sin intencionalidad' también se puede

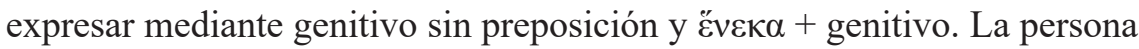
responsable no persigue con su acción controlada la situación que resulta de ella (Il. 20.297-8; Od. 19.159).

3) Responsable con intencionalidad: persona que desencadena el estado de cosas con una acción controlada e intencionada que tiene como fin el resultado que se deriva de ella. La diferencia entre el responsable con intencionalidad y el agente es, en numerosas ocasiones, mínima. La expresión de un responsable que provoca intencionadamente los sentimientos del sujeto parece estar reservada para víó + genitivo (Il. 4.497-8: aquí el responsable está ya muy próximo a un agente).

La autora extrae, entre otras, la conclusión de que el genitivo sin preposición se emplea generalmente como expresión del denominado

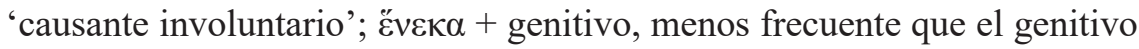
sin preposición, puede expresar tanto el 'causante involuntario' como el 'responsable sin intencionalidad', mientras que el 'responsable con intencionalidad' se expresa mediante vं $\pi$ ó + genitivo.

Con respecto al empleo de expresiones de causa con referente humano como circunstantes de otros verbos distintos de los de dolor y de cólera, es muy reducido el empleo como circunstante del genitivo sin preposición: las formas casuales han sido sustituidas por sintagmas preposicionales y Conti Jiménez analiza aquellos que las gramáticas tipifican como expre-

$6 \quad$ Conti Jiménez 1999. 
siones de la causa en Homero con el objetivo de determinar si los tres subtipos de causa anteriormente citados encuentran un reflejo formal en los poemas. Los sintagmas estudiados por la autora son $\delta 1 \alpha$ + acusativo,

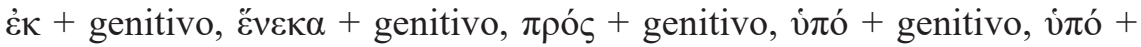
dativo. Los resultados obtenidos son los siguientes: a) tan solo ह̌veк $\alpha+$ genitivo se emplea como expresión del 'causante involuntario': Il. 1.298-9 y 6.328-9; b) todos los sintagmas preposicionales pueden expresar lo que la autora denomina 'responsable'. Con la excepción de los ejemplos de

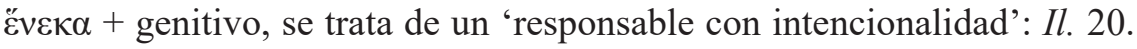

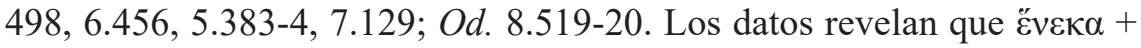
genitivo está especializado en la expresión de las variantes conceptuales de la causa que se encuentran más alejadas de la noción del agente, a saber: el 'causante involuntario' y el 'responsable sin intencionalidad' ${ }^{7}$. Estas nociones forman parte de un continuum cuyos extremos están definidos por el 'causante involuntario', por un lado, y el agente, por otro. La diferencia semántica y funcional entre ambos extremos se hace patente en

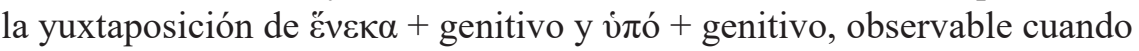
Iris va en busca de Helena y la encuentra bordando un manto púrpura en el que se representan las numerosas penalidades que troyanos y aqueos "por

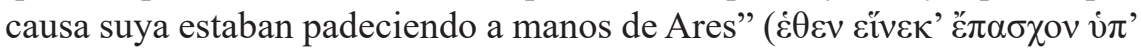
"A $\eta$ $\varsigma \pi \alpha \lambda \alpha \mu \alpha \dot{\alpha} \omega v$ Il.3.128). Pasajes como este demuestran que las formas situadas en el extremo izquierdo ('causante involuntario') del continuum son incompatibles con la expresión de las nociones situadas en el extremo derecho (agente), así como las situadas en el extremo derecho lo son con las nociones del extremo opuesto.

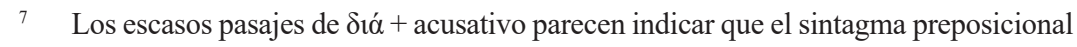
expresa el responsable que actúa de forma intencionada, pero sin ejercer un control pleno sobre el estado de cosas descrito en la oración. La ausencia de ejemplos de $\delta$ í + acusativo como expresión del causante indirecto no impide suponer, en opinión de Conti Jiménez, que este sintagma preposicional también ocupe una parcela conceptual relativamente alejada de la noción del agente. De hecho, de los sintagmas preposicionales analizados, tan solo

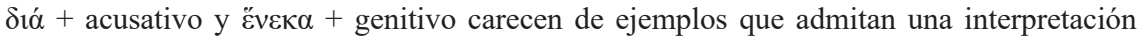
como expresiones del agente y el griego posterior tampoco proporciona ejemplos de $\delta$ ió + acusativo como expresión del agente, a pesar de que el sintagma preposicional se ha convertido ya entonces en la expresión más habitual de la causa. Incluso las oraciones con una pasiva morfológica se prestan poco a una interpretación de $\delta$ ió + acusativo como agente. En el caso de $\dot{\varepsilon} \kappa+$ genitivo, $\pi \rho \cos +$ genitivo, vं $\pi$ ó + genitivo y vं $\pi$ ó + dativo, por el contrario, existen ejemplos de oraciones pasivas que propician una interpretación de los sintagmas preposicionales en términos de agente (Il. 2.668-9, 11.831, 6.134-5, 16.490-1). 
López Gregoris, en un trabajo anterior al de Conti Jiménez, analiza desde un punto de vista léxico la presunta responsabilidad de Helena en la guerra de Troya, tomando como referencia los textos homéricos y utilizando los conceptos de 'culpa pasiva' y 'culpa activa', que, según la autora, se entremezclan dentro de la Ilíada. A pesar de que el propio poema señala tres responsables directos y activos de la guerra - Paris, los dioses en general y Afrodita en particular-, a causa de un concepto pasivo de la culpa Helena se considera como culpable visible y final de las hostilidades. A este concepto de pasividad en la culpa le corresponde una de las dos posibilidades de justificación de la guerra que aparecen en los poemas homéricos: no la huida, sino el rapto, de modo que se establece la secuencia 'rapto - culpa pasiva'. Paris admite que su acción fue la de 'raptar' a Helena (Il. 3.444, $\alpha \rho \pi \alpha ́ \xi \alpha \varsigma)$, bien por inducción de Afrodita, bien por deseo propio, de donde se deduce que Helena no es más que el objeto de la acción sobre el que recae la consecuencia de aquello que realiza el sujeto y lo sufre o lo padece pasivamente; por tanto, aunque Paris fuera el motor que puso en movimiento todo el engranaje bélico, Helena fue el objeto codiciado por unos y por otros, el motivo final y pasivo de sus disputas.

Frente a la consideración que Helena tiene con respecto a sí misma, las palabras de los guerreros hacen hincapié en su hermosura sin parangón (Il. 3.156-8) y en su asociación con las riquezas y con el honor que conlleva poseer a semejante mujer (cliché homérico que se concreta en la fórmula

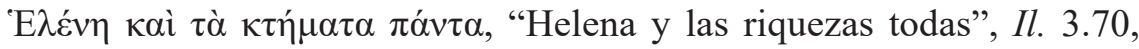
$3.255 ; 7.401)$. Este proceso de cosificación tiene su plasmación sintáctica en el hecho de que Helena sea el objeto pasivo de la acción que sobre ella realiza Paris (ö́ $\gamma \varepsilon v)$, así como el sujeto paciente del término correspondiente de este proceso léxico ( $\check{\varepsilon} \pi \varepsilon \sigma \theta \alpha \mathrm{l})$. Lo que constituye la causa de la guerra de Troya es, en consecuencia, el rapto de Helena, no su huida9 .

$8 \quad$ López Gregoris 1996.

9 Los poemas homéricos no nos dicen nada acerca de que Helena recibiese algún castigo por sus acciones pasadas. Según Hirvonen (1968: 124-5), esto se debe a que en los poemas prevalece la visión de que la causa de la guerra de Troya "fue un abuso de hospitalidad. Tal hospitalidad era obligatoria, dictada por Zeus, de tal modo que abusar de ella era un sacrilegio. La seducción de la esposa y la inmoralidad eran sencillamente manifestaciones de este abuso (...)"y, por tanto, los griegos consideraban como una obligación religiosa destruir la ciudad. La idea de no recuperar a Helena era intolerable, no tanto porque se considerase que debía ser devuelta al ultrajado Menelao, como porque ella era el símbolo definitivo de la victoria sobre los troyanos. 
Junto a la versión argumental del origen de la guerra de Troya basada en el rapto de Helena y, por tanto, en un concepto pasivo de su responsabilidad, puede distinguirse la otra posibilidad, es decir, la culpa activa de Helena a través de un acto voluntario de huida de Esparta junto a Paris. López Gregoris se pregunta si existen datos en la épica homérica que testimonien la culpabilidad activa de Helena o si hay algún pasaje en donde se manifieste el deseo de huir por parte de Helena. Ruiz de Elvira defiende la voluntariedad de Helena basándose, entre otras cosas, en el empleo del verbo ह̌ $\pi \varepsilon \sigma \theta \alpha l$ (Il. $3.173-4)^{10}$. Ahora bien, si de aquí se deduce que ह̌ $\pi \varepsilon \sigma \theta \alpha \mathrm{l}$ indica deseo claro y voluntario de huida, entonces $I l$. 24.763-4 entraría en franca contradicción. Los verbos enfrentados son $\varepsilon \pi \pi \varepsilon \sigma \theta \alpha$, referido a Helena y á $\gamma \varepsilon ı v$, referido a Paris. Helena 'sigue' a Paris (Il. 3.174, 447) y Paris 'se lleva' a Helena (Il. $3.401,404 ; 6.301 ; 24.764)$. Inicialmente parecen enfrentados desde el punto de vista del significado, porque no hace falta 'llevarse' a quien 'sigue'; a

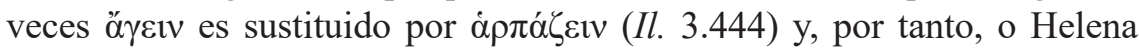
sigue voluntariamente a Paris — argumento de la huida - o Paris se lleva a Helena - argumento del rapto.

Para dilucidar la cuestión, López Gregoris utiliza un argumento de semántica estructural: si se estudia el funcionamiento del verbo $\check{\pi} \pi \varepsilon \sigma \theta \alpha$ con indistinción de contextos, se aprecia que funciona desde el punto de vista de la lexemática verbal como segundo término de una relación complementaria causativa, es decir, como verbo complementario de un causativo antecedente (así se constata en $I l$. 12.398). Se trata de una relación - muy utilizada en las lenguas clásicas - entre dos acciones verbales: el término causativo es el antecedente del término complementario, que es su consecuente. Entre el término causativo y su complementario existe, a menudo, no solo una relación semántica, sino también morfológica. Uno de los contextos más frecuentes en donde funciona este verbo es el ámbito militar, en el cual las tropas o los pueblos 'siguen' a sus caudillos, quienes 'dirigen la formación', 'dan las órdenes' o 'están al frente' (Il. 13. 689-91; 13.489-92). La consideración de Helena como objeto valioso y esposa del héroe vencedor tiene una plasmación lexemática que corresponde a la complementariedad causativa referida al matrimonio; la primera acción precipita la segunda, estructurándose en estos términos:

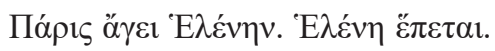

$10 \quad$ Ruiz de Elvira 1974. 


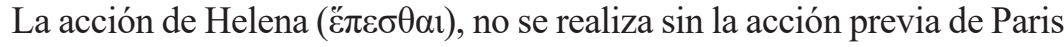
(óyeıv) y ambas, ensambladas, dan lugar a la relación lexemática causativa del matrimonio, que como tal aparece plasmada en los textos. A la manera de proceder de Paris le corresponde léxicamente la acción de ह̌ $\pi \varepsilon \sigma \theta \alpha$ y en esa correspondencia no es pertinente plantearse el grado de voluntariedad

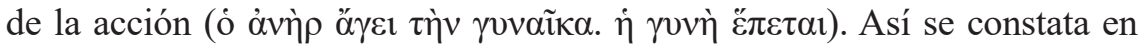
Il. 3.173-5 y 447, en donde se emparejan el nombre para la esposa con el verbo que le corresponde, como antes aparecían juntos el nombre del esposo

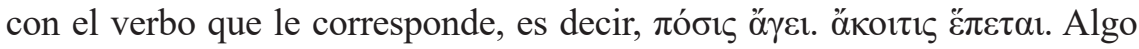
similar sucede en latín, donde a la acción del novio le corresponde el verbo ducere y a la acción de la mujer le corresponde nubere, ire, venire o sequi. La conclusión de López Gregoris es que con respecto a la cuestión de la responsabilidad de Helena en la guerra y la voluntariedad de su acción, los datos solo avalan uno de los dos argumentos míticos, el de la culpabilidad pasiva y su consecuente, el rapto, el cual se acomoda mítica, sintáctica y lexemáticamente a la expresión léxica que aparece en los textos.

Hasta aquí hemos revisado la cuestión, recurrente en cualquier estudio sobre Helena en la épica, sobre su responsabilidad en la guerra de Troya. Inseparablemente unida a esta cuestión se encuentra otra más, a saber: la supuesta ambigüedad del personaje. Worman, por ejemplo, reconoce el predominio de un retrato favorable de Helena en la Ilíada, pero, al mismo tiempo, afirma que "el propio poeta homérico parece responder a una tradición preexistente de historias que se contradicen, como se demuestra en las tensiones entre el retrato más indulgente de Helena, que él favorece ostensiblemente, y las implicaciones más sombrías que permite que se infiltren" ". A la imagen favorable de Helena, alentada por el poeta épico, vendría a sumarse, por tanto, una tradición alternativa que retrata su naturaleza peligrosa.

La investigación de Clader distingue, precisamente, dos caras de Helena en diferentes niveles del poema: en el nivel de la acción épica es un personaje poco definido, instrumental o pasivo. Ahora bien, "la dicción que rodea a Helena en la Ilíada sugiere, sin embargo, un personaje que es más netamente amenazador, menos favorable" 12 y tales rasgos evitan que la elección heroica hecha por Aquiles de una vida corta, pero gloriosa, se vea reducida al absurdo a causa de los reproches que Helena le hace a Paris y el desagrado que le inspira en el presente esa relación conyugal por

\footnotetext{
11 Worman 2001: 20.

12 Clader 1976: 17.
} 
la que han muerto tantos héroes de ambos bandos. Helena se llama a sí misma 'perra' tres veces en la Ilíada y una en la Odisea (Il. 3.180, 6.344 y 356 ; Od. 4.145), manifestando el pesar y la vergüenza que le produce haber sido la causa de la guerra. Si se dejan aparte los símiles y las metáforas, la palabra $\kappa v ́ \omega v$ aparece cuarenta veces en la Ilíada y en treinta y cinco de esas apariciones hace referencia a perros que devoran cadáveres humanos. Ser pasto de los perros constituye una amenaza para un héroe épico, puesto que le privaría de una muerte honorable. Por tanto, "el hecho de que Helena se llame a sí misma kú podría sugerir que la base de este reproche esté en conexión con la terrible amenaza que los perros representan para los héroes"13.

Además de referirse a sí misma como kúœv, en $I l .6 .344$ también se

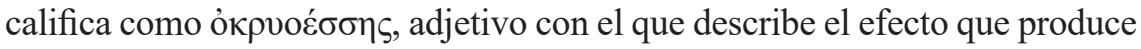
sobre los demás, a quienes causa un miedo escalofriante. En Il. 3.404 utiliza

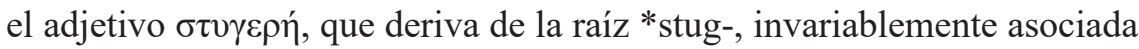
con la muerte en todos los contextos donde se encuentran palabras con dicha

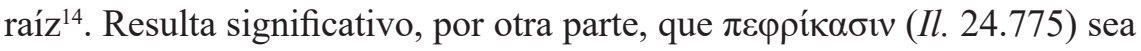
la última palabra que pronuncia Helena al final del poema, en el lamento fúnebre por Héctor. El verbo $\varphi \rho i ́ \sigma \sigma \omega$ significa "erizarse, estremecerse de terror, temblar": a los troyanos se les eriza el pelo ante Diomedes "como

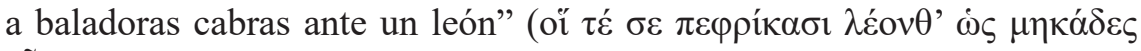

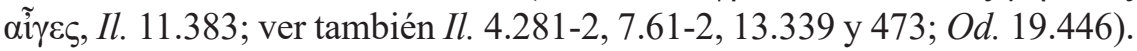
Los contextos en los que aparece $\varphi$ pí $\sigma \omega$ siempre son violentos o están conectados con la guerra y "en los dos ejemplos en los que el verbo lleva objeto directo - el verbo aparece en la misma forma en ambos casos - uno de ellos es el gran guerrero Diomedes, el otro es Helena. Sin duda, Helena es la única referencia que no encaja de manera inmediata con el patrón, a menos que se la considere como un personaje más estrechamente identificado con la guerra y la violencia de lo que parecería obvio a primera vista en su lamento por Héctor"15.

13 Clader 1976: 18. Conviene añadir, no obstante, que esta no es la única conexión que sugiere la Ilíada en la comparación de un ser humano con un perro: también está presente una indicación de avaricia, codicia o el incontenible deseo de comer no regido por las normas de cortesía. A este respecto, véase el trabajo de Graver (1995).

14 Clader 1976: 20, esp. n. 30.

15 Clader 1976: 21-2. 
Para cerrar las referencias que apuntan a un retrato negativo y amenazador de Helena, la autora cita la única aparición del adjetivo $\dot{\rho} \imath \varepsilon \delta \alpha v \tilde{\eta} \varsigma$, cuya raíz "parece implicar un estremecimiento de terror ante la muerte en combate, ante los dioses o ante las consecuencias de una violación de la confianza" ${ }^{16}$. Con este adjetivo Aquiles califica a Helena cuando llora la

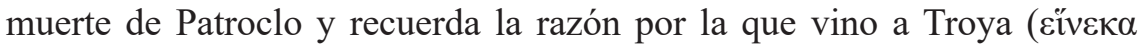

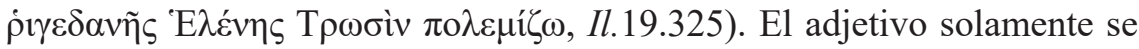
utiliza aquí con esta forma y no hay ejemplos de él en la Odisea, aunque sí se localizan en ambos poemas otras formas de la misma raíz ( $\dot{\rho} \tilde{z} \gamma o \varsigma$, Od. 5.472

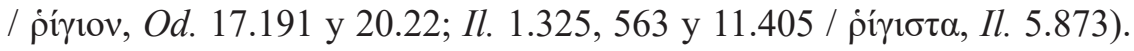

En resumen, para que el auditorio no olvide que Helena es la causa e incluso el símbolo viviente de una guerra terrible, Homero ha utilizado elementos de dicción referidos a ella que hacen la relación explícita. La aparente futilidad de la contienda, que podría venir sugerida por la escena entre Helena y Paris y por los reproches que ella le dedica en repetidas ocasiones, se contrarresta, así, por medio de la inclusión en la dicción del poema de unas palabras que caracterizan a Helena como mujer peligrosa y amenazadora. Desde una perspectiva similar a la expuesta hasta aquí, Collins opina que "las caracterizaciones flexibles e incluso paradójicas de los [personajes] no-guerreros, en cuyo nombre existe el heroísmo, también les permiten asumir las contradicciones que, de otro modo, podrían socavar la ética heroica" y, por otra parte, "el hecho de que la responsabilidad de Helena sea expresada ante todo por la propia Helena (...) contribuye a los intereses ideológicos del poema. En una palabra, solo Helena puede censurar a Helena sin poner al descubierto la paradoja que el poema desea mantener oculta: que el mismo acto que exige que se libre una guerra por ella también la condena desde el punto de vista del poema y la convierte en un objeto indigno de luchar por él" 17 .

Los trabajos de Clader y Collins subordinan la caracterización de Helena al sustrato ideológico de la Ilíada y tal enfoque tiene la virtud de no incurrir en valoraciones sobre el personaje que son ajenas a los fundamentos éticos y estéticos de un poema que es heredero de una larga tradición oral. Tales valoraciones proceden, a menudo, de una lectura de la obra en clave psicológica. Para ilustrar mi punto de vista me detendré especialmente en el análisis de la caracterización de Helena en el canto

16 Clader 1976: 22-3.

17 Collins 1988: 14 y 57. 
3 de la Ilíada. La diosa Iris adopta aquí la figura de Laódice, cuñada de Helena, y se dirige a ella con un imperativo "ven aquí" ( $\delta \varepsilon \tilde{v} \rho$ ' i $\theta$ ı Il. 3.130) para anunciarle el combate singular que está a punto de tener lugar entre Alejandro y Menelao. Helena está tejiendo un manto púrpura donde se representa la guerra entre troyanos y aqueos, "que por causa

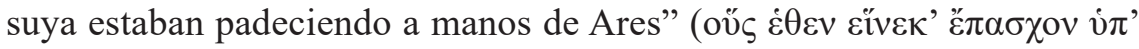

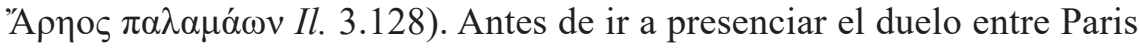
y Menelao, la diosa Iris "le infundió el dulce deseo de su anterior marido,

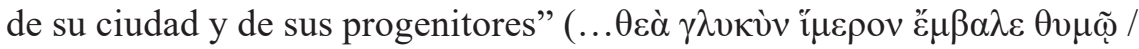

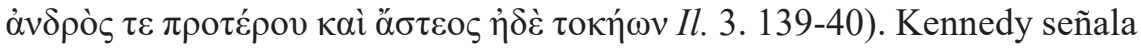
que "la intrusión del deseo sugiere que este no había existido de manera consciente. Hasta ahora ha sido suprimido por la realidad de la presencia de Paris o por la ocupación de Helena en su manto. En el pasaje siguiente se convertirá en partidaria de los griegos y esto explica la actitud con la que recibe a Paris tras el frustrado duelo" ${ }^{18}$. Cuando llega a las puertas Esceas, encuentra a Príamo rodeado de otros siete ancianos, que admiran la belleza de Helena hasta el punto de compararla con las diosas inmortales y afirman que es comprensible que aqueos y troyanos libren una guerra por semejante mujer; también expresan, no obstante, el deseo de que regrese a su patria para evitarles futuras desgracias a todos los troyanos (Il. 3.156-60). En la reacción de los ancianos se mezclan la atracción que les causa Helena con la percepción del peligro que supone para Troya. El rey Príamo le dirige palabras tiernas y le pide que se siente a su lado para ver desde la torre a troyanos y aqueos; no la considera culpable de

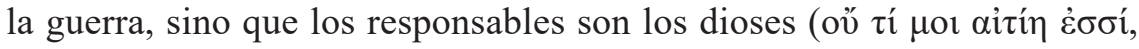

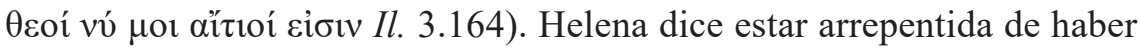
abandonado a su familia por seguir a Paris, al tiempo que lamenta no haberse quitado la vida entonces. Se llama a sí misma 'cara de perra' y manifiesta de esta manera la dolorosa conciencia de todo lo que ha ocurrido por su causa (Il. 3.173-80):

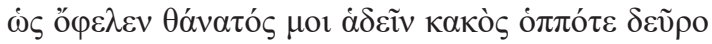

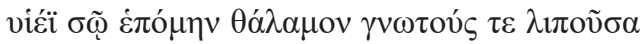

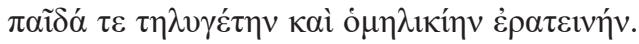

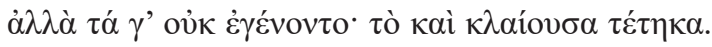

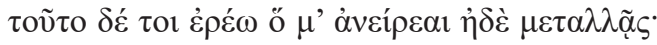

18 Kennedy 1986: 10. 
ỡ

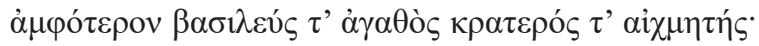

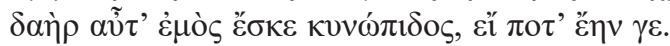

¡Ojalá una muerte cruel me hubiera sido grata cuando segui hasta aqui a tu hijo, abandonando tálamo y hermanos, a mi niña tiernamente amada y a la querida gente de mi edad! Pero no sucedió así, y por eso estoy consumida de llorar. Te voy a responder a eso que me preguntas e inquieres: ese es el muy poderoso Agamenón atrida, a la vez buen rey y esforzado guerrero. Era mi cuñado, de mí, cara de perra, si eso alguna vez sucedió.

Estas primeras palabras que Helena pronuncia en el poema constituyen la expresión verbal de ese sentimiento de responsabilidad (involuntaria) ya implícito en la escena bordada por ella misma en el manto que estaba tejiendo hace unos instantes: غ̇ंó $\mu \eta v$ (174) la presenta como seguidora de Paris y, por tanto, como sujeto pasivo del rapto, mientras que el participio $\lambda \iota \pi$ ov $\sigma \alpha$, al final del mismo verso, pone de relieve el doloroso reconocimiento de todo lo que dejó atrás por seguir al príncipe troyano. Roisman ve en estos versos el propósito por parte de Helena “de cultivar la simpatía y buena voluntad de alguien cuya protección necesita, adoptando una pose femenina estereotipada (del mismo modo que al tejer había adoptado una ocupación típicamente femenina): humilde, necesitada e inofensiva. Esto demuestra su habilidad y competencia a la hora de hacer que la gente se sienta bien y de cuidar de sí misma por ser una mujer no grata en un entorno hostil" ${ }^{19}$. La autora también considera que la referencia a Paris como "tu hijo" (viéï ođ̃ Il. 3.174), al evitar llamarlo por su nombre, "borra cualquier conexión personal entre ella misma y su marido troyano y expresa sutilmente su aversión hacia él. También parece implicar a Príamo en la conducta de su hijo. (...) Esto no significa que ella deje de aceptar su propia responsabilidad. Así lo corroboran sus repetidas afirmaciones de autocensura hasta el final del poema".

Las sutilezas psicológicas que Roisman extrae de la lectura de los versos anteriormente citados no contemplan su cualidad marcadamente patética, cualidad que, en mi opinión, es la que el auditorio percibiría por encima de todo en el momento de la ejecución oral del poema. La interpretación que hace la autora del sintagma viéi $\sigma \tilde{\omega}$ introduce en la relación Príamo-Helena una nota de ambigüedad que resulta gratuita $y$, además, parece pasar por alto que la supuesta hostilidad latente de Helena

19 Roisman 2006: 13-4. 
hacia su suegro se podría explicar por una razón ajena a la voluntad de la propia Helena y anunciada por el poeta en versos anteriores: la acción de la diosa Iris, que "le infundió el dulce deseo de su anterior marido, de

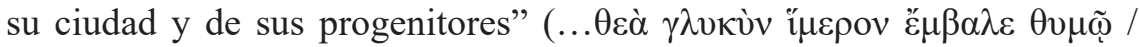

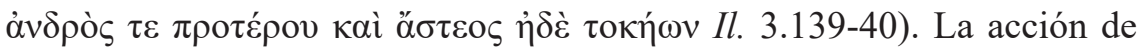
la diosa sobre la mente de Helena constituye un recurso del poeta épico, no para caracterizar a Helena, sino para intensificar el patetismo de su

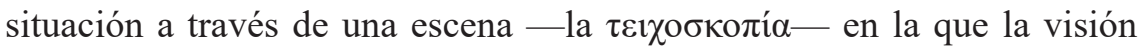
de los guerreros griegos desde lo alto de las murallas hace que el dolor de Helena por sus acciones pasadas se desborde y se concrete en las duras palabras que dirige contra sí misma.

Helena no ve desde la torre a sus hermanos, Cástor y Pólux, y se plantea dos opciones para explicarse su ausencia: o no han venido a Troya con los aqueos o sí han venido, pero prefieren ocultarse a la vista de los demás por causa de la mala fama de su hermana (Il. 3.236-42). Inmediatamente después de estos versos, el poeta nos informa de que ambos están muertos y que sus cuerpos reposan en Lacedemonia (Il. 3.243-4). Que Helena ignore por completo el destino de sus hermanos constituye otro elemento de intenso $\pi \alpha ́ \theta$ o $\varsigma$ que pone de relieve el aislamiento en el que vive dentro de las murallas de Troya. Sería excesivo ver aquí, a la manera de Roisman, que el interés por Cástor y Pólux no revela solo la añoranza de la familia, sino también una crítica implícita de Helena hacia los troyanos y "otro modo de hacerle saber a Príamo que, a pesar de que depende de él, no ve a su familia como propia y que durante los últimos nueve años ha estado alejada de su familia 'real' en Esparta". Además, según esta autora, el odio e indignación que indirectamente destilan las palabras de Helena constituirían un "esfuerzo por afirmar su personalidad en medio de circunstancias difíciles" 20 .

Paris no muere a manos de Menelao en el combate singular que tiene lugar entre ambos porque Afrodita lo envuelve en una densa bruma, lo lleva al palacio y lo deposita en el lecho que comparte con Helena. Afrodita, bajo la apariencia de una anciana, le dice a Helena que Paris la está esperando en su alcoba e intenta estimular su deseo hablándole de la belleza del joven, que por su aspecto radiante no parece venir de pelear con otro hombre (Il. 3.390-4). Mientras que el poeta no nos dice nada acerca de que Helena reconociese a Iris bajo la apariencia de su cuñada Laódice, sí nos informa de que enseguida comprende que la anciana

20 Roisman 2006: 15. 
cardadora que la insta a reunirse con Paris es, en realidad, Afrodita (Il. 3.395-8). El hecho de que se muestre consciente de ser un instrumento de la divinidad nos indica, como señala Reckford, que "Homero no utiliza a Helena solamente para demostrar el poder de los dioses a través del cumplimiento de la guerra de Troya. También plantea (y tal vez esto sea nuevo en su poema) qué sentiría una persona que fuese utilizada como títere de los dioses" ${ }^{21}$. Su actitud hacia la diosa (Il. 3.399-412) contrasta notoriamente con la sumisión y la docilidad de sus encuentros anteriores con Iris y Príamo: le pide que no pretenda seducirla con mentiras ni llevarla a algún lugar más lejano que Troya para complacer a otro favorito suyo; para Helena es evidente que Menelao ha sido el vencedor del combate singular y piensa que ahora Afrodita quiere impedir que su anterior marido se la lleve de regreso a casa. Roisman señala que en el verso 404 Helena utiliza la palabra oǐ $\alpha \delta$ ' para designar a Esparta y que aquí "es un término mordaz que evoca las palabras de Afrodita a Helena al comienzo de esta escena: "Ven aquí, Paris te llama para que vengas

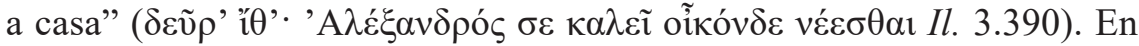
estas palabras, Afrodita identificaba el hogar de Helena como el hogar de Paris. Helena ya había indicado en la $\tau \varepsilon £$ фобколí $\alpha$ que no consideraba Troya como su hogar. Ahora le dice esto a Afrodita inequívocamente"22. Helena, por tanto, no está dispuesta a sucumbir a los engaños de la diosa (Il. 3.406-12):

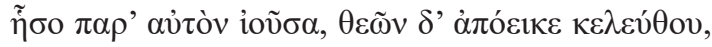
$\mu \eta \delta$ ' हैं

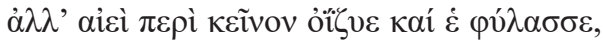

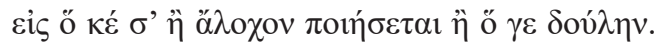

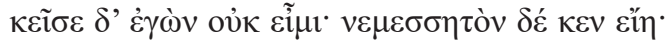

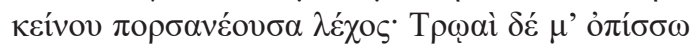

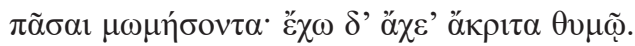

Ve y siéntate a su lado, apártate de la senda de los dioses y no regreses ya sobre tus pasos al Olimpo. Quédate para siempre gimoteando a su alrededor y vela por él hasta que te haga su esposa o incluso su esclava; pero yo alli no pienso ir, ivituperable sería!, a compartir su lecho. Todas las troyanas después me lo reprocharán y ya son innumerables los pesares de mi corazón.

$21 \quad$ Reckford 1964: 17.

22 Roisman 2006: 17. 
Clader observa que "ningún otro personaje homérico reprende a una divinidad con palabras tan duras y esto debe de implicar que existe entre Helena y la diosa una cercanía nada común" ${ }^{23}$. Helena invierte los papeles y es ella la que invita a la diosa a entregarse a la pasión. Se niega, además, a ir al lecho de Paris porque, si lo hiciera, se ganaría con ello el reproche de las mujeres troyanas. Tal explicación puede parecer ilógica tras casi diez años de convivencia marital, pero revela la preocupación de Helena por su reputación en una ciudad en la que no es bien considerada por la mayoría. La diosa, encolerizada, amenaza a Helena con abandonarla y con suscitar entre griegos y troyanos un odio tal hacia ella que ocasione su muerte (Il. 3.413-7). Helena, atemorizada, se cubre con un velo para pasar inadvertida entre las troyanas y camina en silencio tras la diosa, que la conduce hasta la alcoba de Paris. Cuando se reúne con él, le dirige palabras muy duras (Il. 3. 428-36):

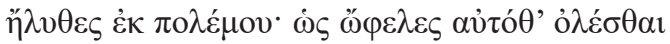

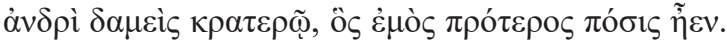

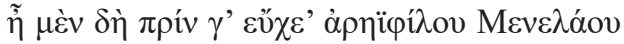

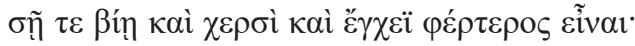

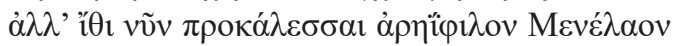

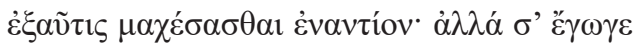

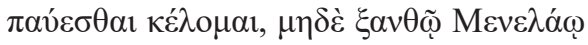

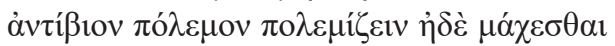

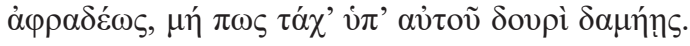

Has vuelto del combate. ¡Ojalá hubieras perecido allí doblegado por el esforzado guerrero que fue mi anterior marido! Antes te jactabas de ser superior a Menelao, caro a Ares, por tu fuerza, por tus puños y por tu manejo de la lanza. Pues vete ahora y desafía a Menelao, caro a Ares, a luchar de nuevo en combate singular. Pero yo por mi parte te aconsejo que desistas y que no te enfrentes ni libres con el rubio Menelao un combate cuerpo a cuerpo temerariamente, no sea que pronto sucumbas bajo su lanza.

Sus tres primeras palabras (ฑ̋ $\lambda v \theta \varepsilon \varsigma \dot{\varepsilon} \kappa \pi \mathrm{o} \lambda \dot{\varepsilon} \mu \mathrm{ov}, 428)$ no son una mera afirmación orientada a señalar dónde ha estado Paris antes de su encuentro, sino que, en opinión de Roisman "contienen una fuerte dosis de sarcasmo: sugieren que un hombre que acaba de llegar del combate no se tumba en el lecho adornado de una alcoba perfumada, ataviado

23 Clader 1976: 13. 
con hermosos ropajes y con la apariencia de quien viene de un baile" 24 . Aunque la autora extrae demasiados matices de las tres primeras palabras del verso 428, su interpretación parece basarse en las palabras que Afrodita le dijo anteriormente a Helena para estimular — sin éxito - su deseo de ir a reunirse con Paris (Il. 3.390-4):

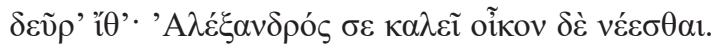

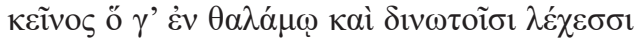

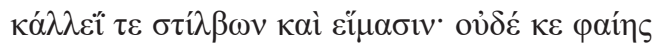

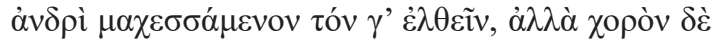

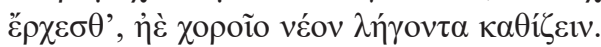

Ven aqui. Te llama Alejandro para que regreses a casa. Alli está él, en el tálamo y en el torneado lecho, esplendente por su belleza y su atavío. No dirías que viene de pelear con un hombre, sino que va a danzar o que, dejando el baile, se acaba de sentar.

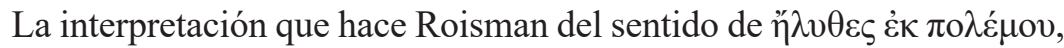
no solo viene respaldada por estas palabras de Afrodita, sino también por el propio contenido y tono de los versos 428-36: Helena expresa abiertamente el deseo de que Paris hubiese muerto a manos de Menelao, a quien se refiere enfáticamente como "fuerte guerrero" ( $\alpha \nu \delta \rho i ̀ . . . \kappa \rho \alpha \tau \varepsilon \rho \tilde{Q})$ al comienzo

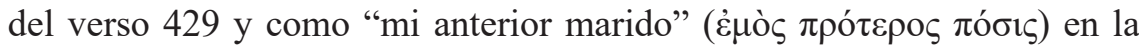
segunda mitad del mismo verso. En los siguientes siete versos (430-6) repite tres veces el nombre de Menelao en posición final: en dos de esas

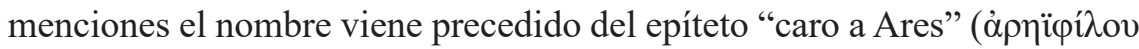

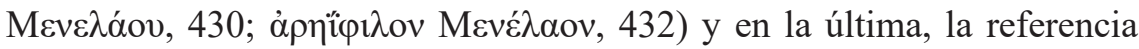

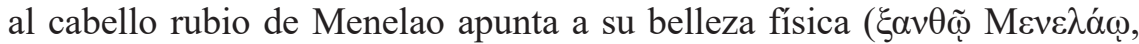
434). Cuando Helena anima a Paris a volver de nuevo al combate ( $\dot{\alpha} \lambda \lambda$ '

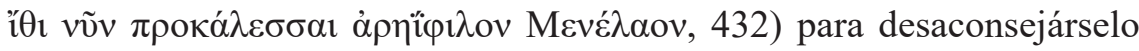

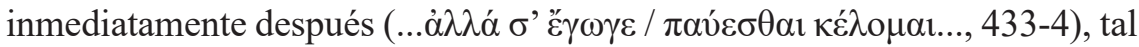
yuxtaposición de órdenes contradictorias contribuye a ensalzar la valentía de Menelao y a escarnecer a Paris por su cobardía. Resulta evidente, por tanto, que el protagonista principal de los versos 428-36 es Menelao, cuya excelencia, reconocida por la propia Helena, revela claramente el desagrado y el desprecio que siente hacia Paris la misma mujer que en otro tiempo abandonó Esparta para irse con él a Troya.

24 Roisman 2006: 21. 
No me parece acertado ver aquí un cambio de opinión de Helena ${ }^{25}$ o que tal supuesto cambio sea testimonio de su amor por Paris ${ }^{26}$. Taplin, por su parte, interpreta estos versos como prueba de la ambivalencia de Helena, atrapada entre su deseo de que Paris muera y, a la vez, que no arriesgue su vida ${ }^{27}$, mientras que Willcock afirma que "la vehemencia de sus críticas demuestra que todavía ama a Paris" ${ }^{28}$. Opino que el tono general de las palabras de Helena en $I l$. 3.428-36 no manifiesta ni ambivalencia ni amor, sino una inequívoca actitud de desprecio por Paris, a quien diversos personajes - no solo Helena - le dirigen duros reproches por su falta de heroísmo en otros lugares del poema ${ }^{29}$. Kirk observa que "todo el discurso es (...) amargamente sarcástico y hostil" y que "parece implicar resentimiento e incluso desprecio" ${ }^{30}$. El propio Paris percibe la hostilidad de Helena y la insta a que no le hable con tanta dureza (Il. 3.438-46):

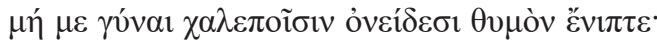

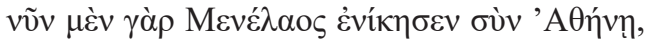

25 Vivante 1985: 95.

26 Hooker 1979: ad 3.433.

27 Taplin 1992: 101.

28 Willcock 1978: ad 3.427.

29 Después de la vergonzosa negativa a batirse en duelo con Menelao, Héctor le dirige a Paris estas duras palabras (Il. 3. 39-40): “¡Calamidad de Paris, presumido, mujeriego y mirón!

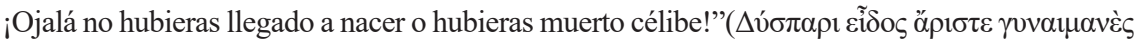

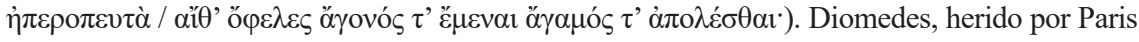
con una flecha, se dirige a él en tono similar (Il. 11. 385-90): “¡Arquero, ultrajador, vanidoso por tus rizos, mirón de doncellas! Si te midieras conmigo cara a cara con las armas, no te socorrerían entonces ni el arco ni las tupidas saetas. Por un simple rasguño en la planta del pie te jactas sin motivo. No me preocupa: como si me acertara mujer o niño irresponsable. Pues

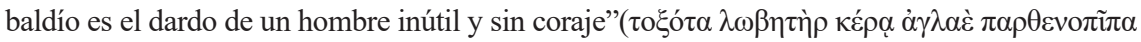

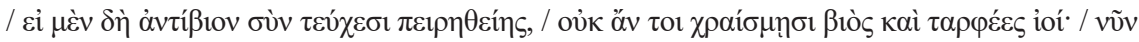

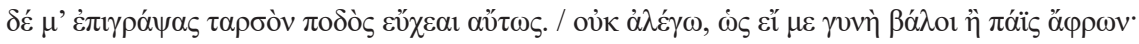

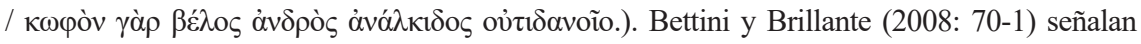
que "la belleza, el interés excesivo por el sexo opuesto, la escasa propensión a involucrarse en la batalla y la tendencia marcada al engaño y a faltar a la palabra dada confieren al personaje rasgos que evocan la naturaleza femenina (...). Estos y otros elementos dibujan una imagen del personaje bastante alejada del ideal heroico". Sin embargo, como arquero, Paris es eficaz, puesto que hiere en el pie a Diomedes y consigue que se retire del combate a la vez que la propia acción del poema desautoriza las palabras de Diomedes. Una cosa es lo que dicen los personajes sobre Paris; otra — bien distinta - lo que dice el narrador al describir lo que él hace. El poema también anticipa que será Paris quien matará a Aquiles.

30 Kirk 1987: ad 3.430-6. 


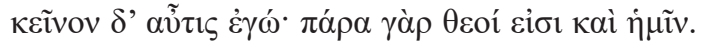

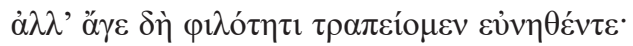

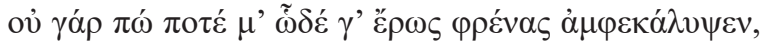

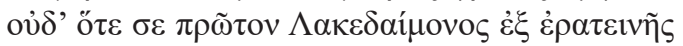

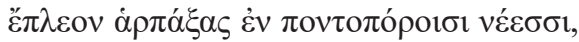

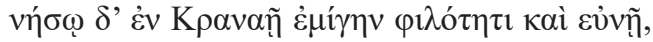

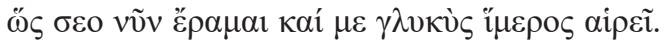

¡Mujer! No mortifiques mi corazón con crueles reproches. Ahora, sí, ha vencido Menelao con ayuda de Atenea, pero en otra ocasión le venceré yo: también nosotros tenemos dioses de nuestra parte. ;Anda, vamos!, acostémonos y gocemos del amor. Jamás la pasión se ha apoderado de mi entendimiento como ahora, ni siquiera cuando, tras raptarte, me hice a la mar desde la amena Lacedemonia en las naves surcadoras del ponto, y en la isla de Cránae me uní contigo en lecho de amor. Así te amo ahora y tan dulce es el deseo que se apodera de mí.

El poeta épico ha logrado aquí un contraste eficaz entre Paris y Helena. Él es un mortal dominado por Afrodita y experimenta ahora en su interior el efecto del poder de la diosa; ni siquiera sintió un deseo tan vivo por Helena cuando la raptó ( $\alpha \rho \pi \alpha ́ \xi \alpha \varsigma 444)$ diez años atrás. El príncipe troyano se presenta a sí mismo, por medio de este verbo, como sujeto agente en la historia pasada del rapto de Helena, mientras que ella se convierte implícitamente en sujeto pasivo de tal acción. Ahora, casi diez años después, se repite el mismo esquema 'agente (Paris) / paciente (Helena)': él le ordena $\alpha \lambda \lambda$ ' ó $\gamma \varepsilon$

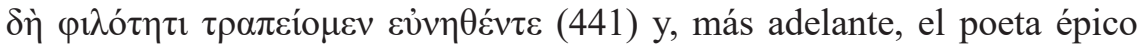
nos dice que Paris "fue el primero al lecho; y su esposa le siguió" ( $\tilde{\eta} \dot{\rho} \alpha$,

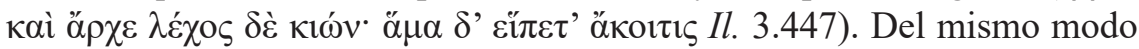
que el sujeto de ó $\rho \chi \varepsilon$ es Paris, la diosa Afrodita había sido el sujeto de este

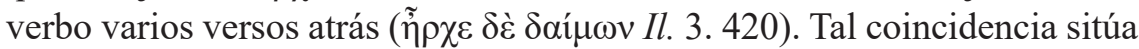
a ambos sujetos como agentes a los que Helena sigue en silencio.

Cuando Héctor va en busca de su hermano para reprocharle su ausencia en el campo de batalla, Paris se justifica de esta manera (Il. 6.335-9):

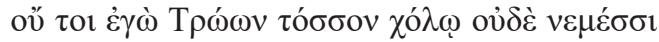

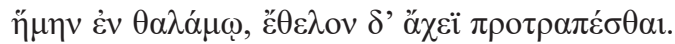

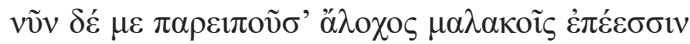

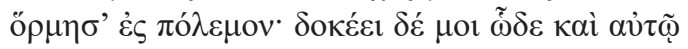

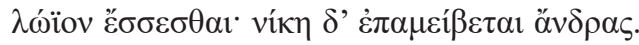


No tanto por ira ni resentimiento con los troyanos estaba sentado yo en el tálamo como por ganas de dar rienda suelta a mi dolor. Ahora mi esposa, que me ha reprendido con tiernas palabras, me ha incitado a volver al combate. También a mí mismo me parece que eso será lo mejor, pues la victoria alterna entre los guerreros.

¿Se refiere el võv $\delta \varepsilon ́$ del verso 337 a la escena entre Paris y Helena del canto 3? Si es así, o bien Paris miente con respecto a la actitud de su

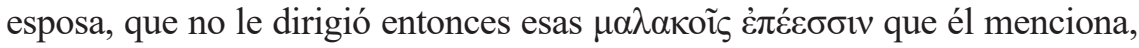
o bien está siendo irónico. Pocos versos después, Helena le va a hablar a Héctor muy desfavorablemente de su hermano, no sin antes dirigir palabras insultantes contra sí misma — como había hecho ante Príamo en el canto 3-:

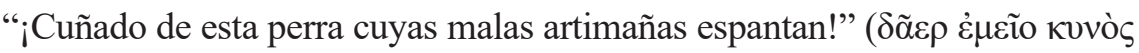

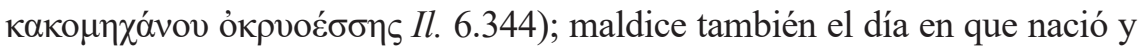
desearía haber muerto entonces (Il. 6.345-8). Su amargura y aflicción alcanzan aquí una mayor intensidad, puesto que Helena ya ha visto la cobardía de Paris, quien no solo es inferior a Menelao, sino también a Héctor. El respeto y las atenciones que le dispensa a este último contrastan con su negativa visión de Paris, al que considera desvergonzado y voluble (Il. 6.349-53):

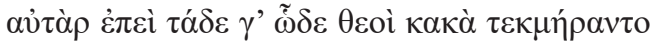

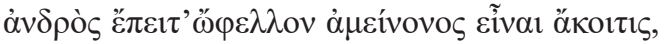

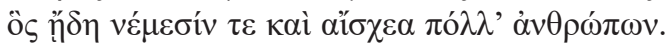

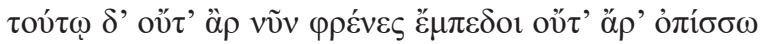

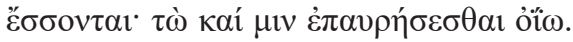

Mas una vez que los dioses decidieron estos males así, ojalá entonces hubiera sido la esposa de un varón mejor, que sintiera la indignación y los muchos oprobios de los hombres. Pero este ni ahora tiene firmeza de ánimo ni la tendrá en el futuro, y por eso creo que también cosechará el debido fruto.

Héctor podría ser, sin duda alguna, ese 'hombre mejor' ( $\alpha v \delta \rho o ̀ \varsigma . .$.

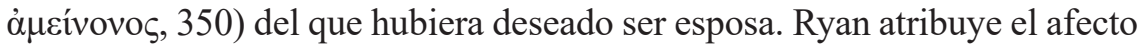
que siente Helena por Héctor al interés personal y a una forma de flirtear con él ${ }^{31}$, pero yo considero preferible atender al contexto en el que tienen lugar las palabras y los actos del personaje, como hace también Roisman cuando afirma que "el afecto y el respeto que Helena le prodiga a Héctor

31 Ryan 1965: 116. 
ponen de manifiesto, más bien, cualidades que todavía no habíamos visto en ella. (...) En su diálogo con Afrodita, Helena había expresado el anhelo de ser un miembro aceptado de la sociedad manifestando preocupación por la opinión que las otras mujeres se formaran acerca de ella. Aquí expresa este anhelo distanciándose de un marido que no conoce la vergüenza y procurando la alianza, no el romance, con el miembro de la familia que es el más respetado de los héroes troyanos" ${ }^{32}$. Por otra parte, Helena le dice a Héctor que se ve a sí misma y a Paris como instrumentos de la voluntad divina y, por tanto, predestinados a su fatal unión (Il. 6.354-8):

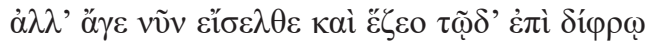

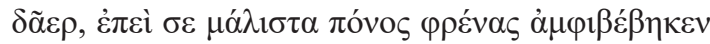

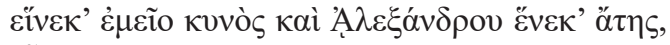

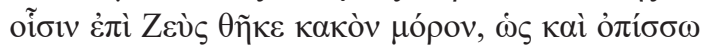

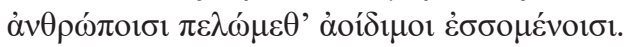

Ea, entra ahora y siéntate en este taburete, cuñado, pues a ti sobre todo es a quien el combate oprime el corazón por causa de una perra como yo y por la ofuscación de Alejandro, a quienes Zeus impuso aciago destino para que a las generaciones venideras sirvamos de materia para sus cantos.

La atribución a Zeus de la responsabilidad en las desgracias sufridas nos hace recordar las palabras de Príamo en el canto 3: para el anciano rey de Troya no es Helena la responsable de la guerra, sino los dioses. No obstante, el final del verso 357 y todo el verso 358 añaden una nota discordante, a saber: la gloria venidera anunciada por Helena contrasta con los versos anteriores (Il. 6.349-53) en los que ella misma manifiesta la actual vacuidad de su relación con Paris.

En los versos finales del canto 24, Andrómaca, Hécuba y Helena, por este orden, lamentan con desgarrado dolor la muerte de Héctor. Helena pone de relieve la diferente actitud que el héroe tuvo hacia ella - al igual que Príamo- en comparación con el resto de la familia real (Il. 24.761-75): Héctor siempre fue amable y amistoso con ella, a pesar de haber causado tantas desgracias a los troyanos; nunca la insultó e incluso la defendió de los insultos de los demás. Expresa nuevamente (como en Il. 3.173-4) el deseo de haber muerto antes de venir a Troya con Paris, puesto que la persona que le manifestaba cariño y amistad ha muerto. Finaliza su lamento haciendo

32 Roisman 2006: 28. 
hincapié en la hostilidad de todos los troyanos hacia ella y la completa soledad en la que se encuentra tras la muerte de su cuñado - aunque no se olvida de mencionar que Príamo "es siempre benigno como un padre"

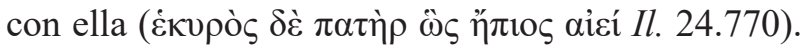

Si comparamos el canto 6 y el 24, podemos constatar de qué distinta manera ha ordenado el poeta épico la aparición de las tres mujeres: en el canto 6 el orden es Hécuba-Helena-Andrómaca; en el canto 24, Andrómaca-Hécuba-Helena. En ambos cantos el lugar especialmente destacado es el último y este hecho hace significativa la despedida de los esposos en el canto 6, pero también el lamento de Helena en el canto 24. Helena es, además, la primera que habla en el poema, cuando conversa con Príamo en el canto 3, mientras que la primera aparición de Hécuba y Andrómaca no tiene lugar hasta el canto 6. Monsacré y Alexiou señalan la inclusión anómala de los lamentos de Helena en el funeral de Héctor, puesto que ella no es miembro de la familia del fallecido ${ }^{33}$ : Alexiou afirma que es a los parientes y amigos cercanos a quienes corresponde participar en los lamentos fúnebres y Monsacré se pregunta por qué motivo es Helena y no Casandra, por ejemplo, quien pronuncia el tercer y último lamento por su hermano, llegando a la conclusión de que la presencia de Helena se debe a su excepcional estatus en la Ilíada: el poeta épico ha decidido que sea ella la primera y la última en hablar — cantos 3 y 24, respectivamente-, del mismo modo que le ha asignado la tarea de tejer un manto en el que se representa la guerra de Troya, estableciéndose así una afinidad implícita entre la labor del poeta y la del personaje. La escena del canto 24 no representa, en opinión de Pantelia, una ceremonia fúnebre de carácter personal o familiar, que ya tuvo lugar en el canto 22, sino que es un ritual de la ciudad entera y para toda ella ${ }^{34}$ : "el énfasis del poema cambia de lo humano y personal a lo universal y trascendente. Los troyanos se reúnen para llorar la muerte de su líder y para celebrar su gloria con cantos que mantendrán viva su memoria y su nombre" 35 . Helena es el personaje más apropiado para este relevante cometido "en virtud de su particular comprensión de la importancia del $\kappa \lambda \varepsilon ́ o \varsigma$ heroico y de la poesía como medio para transmitirlo"36.

\footnotetext{
33 Monsacré 1984: 159; Alexiou 2002: 11-4.

34 Pantelia 2002: 21-7.

35 Pantelia 2002: 25.

36 Pantelia 2002: 21. Frente a la perspectiva de Pantelia, hay enfoques que contemplan dichos lamentos como medio utilizado por el poeta épico para poner en tela de juicio el
} 
Las conclusiones principales a las que podemos llegar tras la revisión del papel de Helena en la Ilíada son las siguientes: 1) el poema nos presenta la guerra de Troya como la consecuencia de una suma de responsabilidades irreductibles a las acciones de una sola mujer; 2) existen argumentos de índole léxica y lingüística que avalan la consideración de Helena como causante involuntaria o responsable sin intencionalidad y que explican la execración que hace de sí misma como manifestación de un concepto de culpa pasiva vinculado con el hecho de haber sido raptada por Paris; 3) la ambigüedad habitualmente atribuida a Helena debería conectarse, no con el $\tilde{\eta} \theta$ os idiosincrático del personaje, sino con diversos factores que van más allá de la (moderna) caracterización por la caracterización misma: el sustrato ideológico del poema y su pertenencia a una larga tradición oral o ese estatus especial de Helena anteriormente mencionado.

\section{Odisea}

En el canto 4 de la Odisea el joven Telémaco llega a Lacedemonia para obtener noticias de su padre mientras en el palacio de Menelao se celebra el banquete nupcial de Hermíone y Megapentes ${ }^{37}$. El rey, que no ha reconocido en él al hijo de Odiseo, le ofrece su hospitalidad y escucha cómo Telémaco admira la riqueza y suntuosidad de su palacio hasta el punto de compararlo con la morada de Zeus (Od. 4.71-5). En lugar de expresar regocijo, Menelao dice que sus ocho años de navegación errante tras la toma de Troya y todos los padecimientos que experimentó en el pasado le han privado del placer de tanta riqueza. Lamenta el asesinato de

código heroico tradicional: las tres mujeres no sólo llorarían la muerte de Héctor sino que en sus palabras de dolor habría una crítica implícita hacia la persecución de gloria por parte del héroe. Desde esta perspectiva, los lamentos de Andrómaca, Hécuba y Helena, aunque no afecten a la acción del poema, irían más allá de los topoi de dolor y cuestionarían ese código en cuyo nombre Héctor entregó su vida. La línea interpretativa que ve en la Ilíada el cuestionamiento del código heroico está representada, entre otros, por los trabajos de Silk (1987), Lynn-George (1988), Martin (1989) y Zanker (1994).

37 Megapentes, cuyo nombre significa "Gran Dolor", no es hijo de Helena, sino que lo engendró Menelao de una esclava ( posición inicial de verso e inmediatamente antes de la mención explícita del nombre de Helena). Tras el nacimiento de Hermíone, los dioses le negaron a Helena la posibilidad de

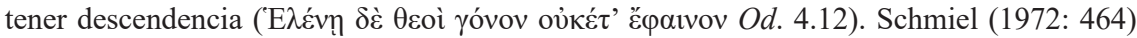
conecta este verso con uno de los primeros indicios en el canto IV de tensión conyugal latente en la pareja formada por Helena y Menelao. 
Agamenón a manos de Egisto gracias al "engaño que hubo de tramar su

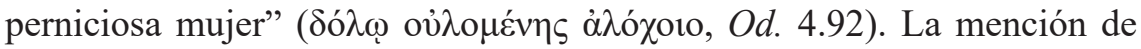
este crimen, como observa Clader, recorre todo el poema ${ }^{38}(O d .1 .35$ y ss.; $3.232-35$ у $255-75 ; 4.495-560 ; 11.427-34$ y 436-9; $13.383-5 ; 24.192-202)$ y su relevancia en el diseño global de la Odisea es que establece un marcado contraste entre el regreso de Odiseo a Ítaca y el de Agamenón a Micenas, así como entre Penélope y Clitemnestra. Por otra parte, cuando Menelao evoca el aciago fin de su hermano en el canto 4, la mención indirecta de Clitemnestra en el citado verso 92 proyecta de manera también indirecta una luz desfavorable sobre Helena, la hermana de la asesina ${ }^{39}$.

La infelicidad de Menelao no solo se manifiesta en la evocación de las desgracias de su familia, sino también en su atormentado recuerdo de Odiseo, al que considera como el héroe que más sufrió de entre todos los aqueos y de quien no sabe si todavía vive o ha muerto. Telémaco se cubre el rostro para ocultar las lágrimas ante el recuerdo de su padre y se produce entonces un breve impasse cuya resolución vendrá de la mano de Helena (Od. 4.113-22):

38 Clader 1976: 27.

39 Esta asociación entre las dos mujeres se hace totalmente explícita cuando Odiseo desciende al Hades y se encuentra con Agamenón, al que dirige estas palabras (Od. 11.436-9):

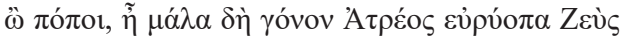

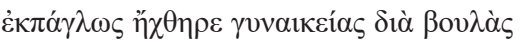

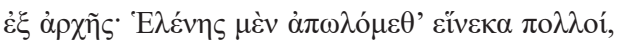

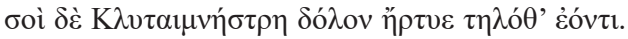

¡Ay, ay! En verdad que Zeus, el que todo lo ve, aborreció de extraordinaria manera a la estirpe de Atreo, ya desde su origen, a causa de los designios de las mujeres: por causa de Helena nos perdimos muchos, y a ti Clitemnestra te preparó una celada mientras te hallabas lejos.

La similar ubicación de los nombres propios dentro de sus respectivos versos pone aquí en paralelo a las dos hermanas en cuanto al carácter negativo de sus acciones. La diferente atribución de responsabilidades viene subrayada, no obstante, por las partículas $\mu \varepsilon ́ v$ y $\delta \varepsilon ́$ que acompañan, respectivamente, a los nombres de Helena y Clitemnestra: mientras que, como afirma Odiseo, él y los demás griegos han sufrido penalidades "por causa de Helena"('E $\lambda \varepsilon ́ v \eta \varsigma . .$.

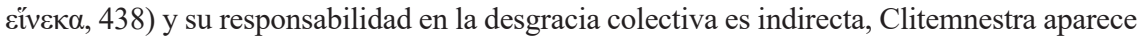
como sujeto de una acción criminal particular, y el nombre de su víctima - Agamenón — se menciona en posición enfática, al comienzo del verso 439, por medio del pronombre $\sigma o i ́$ situado antes del nombre propio K $\lambda \nu \tau \alpha \mu \nu \eta ́ \sigma \tau \rho \eta$. De esta manera, "incluso en su papel de Causa de la Guerra, Helena aparece asociada con Agamenón”, como sucede también cuando Eumeo, sin reconocer todavía a Odiseo, maldice a la estirpe de Helena ( $\dot{\zeta} \omega ̋ \varphi \varepsilon \lambda \lambda$ ' 'E $\lambda \varepsilon \dot{v \eta \eta}$

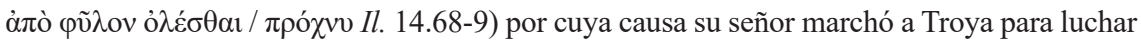

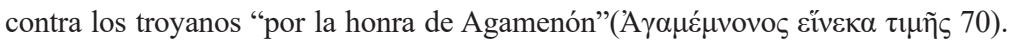




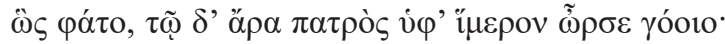

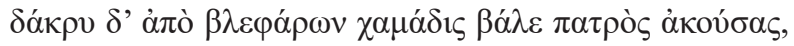

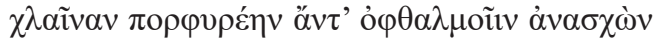

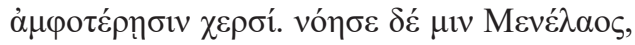

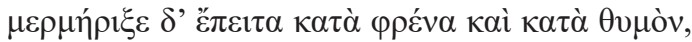

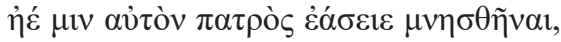

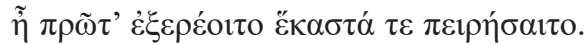

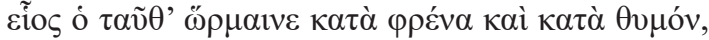

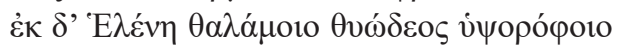

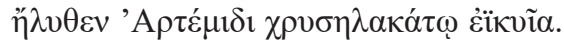

Asi habló, y en él despertó deseo de llorar por su padre: de sus ojos una lágrima cayó en tierra tras oír hablar de su progenitor y levantando con ambas manos el manto purpúreo, se lo puso ante el rostro. Menelao lo observó y estuvo indeciso en su mente y en su corazón entre esperar a que él mismo hiciera mención de su padre, o interrogarle previamente e irle probando en cada cosa. Mientras revolvía tales pensamientos en su mente y en su corazón, salió Helena de su perfumada estancia de elevado techo, semejante a Ártemis, la diosa del arco de oro ${ }^{40}$.

Perceau pone aquí de relieve cómo se expresa lingüísticamente la brusca transición del sujeto masculino (por medio de ó en 120) al sujeto femenino ( $E \lambda \dot{\varepsilon} v \eta$ en 121), "al mismo tiempo que el aoristo $\eta \lambda \nu \theta \varepsilon v$, que subraya la rapidez de Helena, se opone al imperfecto $\rho \mu \alpha \iota v \varepsilon$, que evoca la duración indeterminada de la deliberación de Menelao, y el contraste entre las dos actitudes viene reforzado por el efecto de simultaneidad de las dos acciones expresado por la proposición temporal del verso 120 (cios)" "41. A diferencia de Menelao, que se muestra indeciso con respecto a interrogar a Telémaco, Helena enseguida empieza a hacerle preguntas a su marido $(O d .4 .137-40)$ a la vez que ella misma dice reconocer en el joven que tiene ante sus ojos al hijo del "magnánimo Odiseo" (Od. 4. 141-6):

40 La vinculación de Helena con la diosa virgen contrasta aquí notoriamente con la Ilíada, donde tal vinculación se establece con Afrodita. En opinión de Gumpert (2001: 34), "la comparación puede ser un modo de introducir desde el principio de esta escena una tensión sutil y tal vez cómica en la figura de Helena, una brecha entre lo que Helena parece ser (casta como Ártemis, feliz señora de la casa para Menelao) y lo que sabemos que ella es".

$41 \quad$ Perceau 2011: 143. 


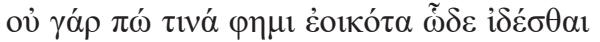

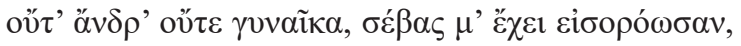

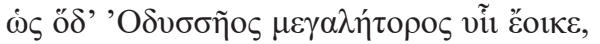

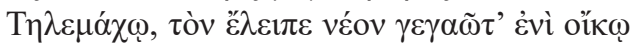

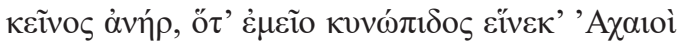

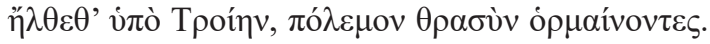

Afirmo que jamás vi persona alguna, ni hombre, ni mujer, tan parecida a otra, y se apodera de mí el asombro al advertir cómo se asemeja este al hijo del magnánimo Odiseo, a Telémaco, a quien dejó recién nacido en su casa el famoso héroe, el día en que, por causa de esta perra que soy yo, los aqueos marchasteis a Troya para emprender una guerra temeraria.

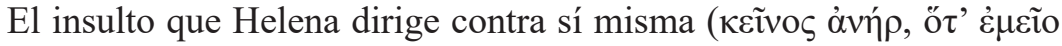

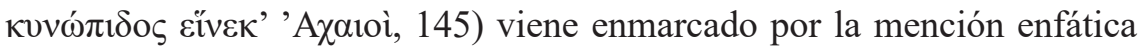
de Odiseo en el centro del verso 143, por la posición también enfática del nombre de Telémaco al comienzo del verso 144 y por la de los aqueos al final del verso 145, de manera que ella se sitúa en el centro de la desgracia individual del héroe y de su hijo, por un lado, y de la desgracia colectiva de los griegos que combatieron por su causa, por otro ${ }^{42}$.

Conocedora de drogas que consiguió en Egipto, decide aliviar las penas de Telémaco y Menelao vertiendo una de ellas en el vino que estaban

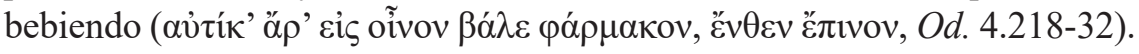
Este $\varphi \alpha ́ \rho \mu \alpha \kappa o v$ también le permite a Helena contar la siguiente historia sobre Odiseo sin reavivar el llanto de sus oyentes, a saber: el héroe entró en Troya disfrazado de mendigo y solo ella fue lo suficientemente sagaz para reconocerlo. Consiguió entonces que Odiseo le confesara los planes de los griegos y colaboró con él dándole información. La droga administrada por la esposa de Menelao aparece descrita por sus efectos: impide el dolor

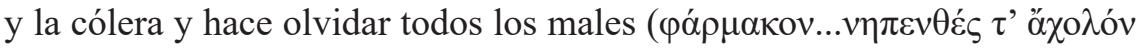

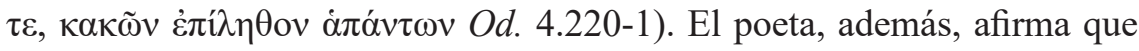
las drogas que la reina egipcia Polidamna le regaló a Helena "muchas son buenas, una vez mezcladas, pero muchas son perniciosas" ( $\varphi \alpha ́ \rho \mu \alpha \kappa \alpha, \pi \circ \lambda \lambda \grave{\alpha}$

42 En versos posteriores también Menelao expresa su sentimiento de responsabilidad por la guerra de Troya: “cuántas desgracias él [Odiseo], sufriendo, experimentó por mí”(ő $\sigma \alpha$

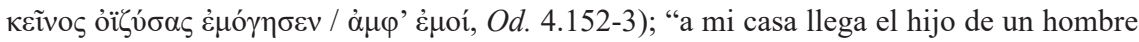

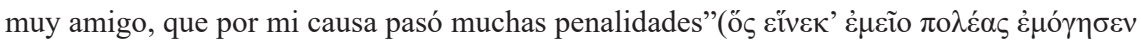
$\dot{\alpha} \varepsilon \dot{\varepsilon} \theta$ ov५, Od. 4.169-70). 


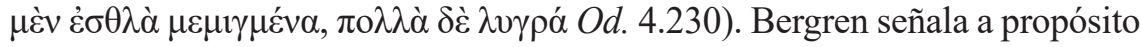

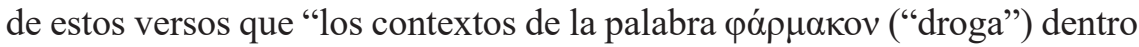
de la dicción del hexámetro describen las drogas como análogas a las dos caras de la poesía en cuanto a su capacidad para curar o destruir". Mientras que en opinión de Bergren (2008) ${ }^{43}$ la historia de Helena funciona como un

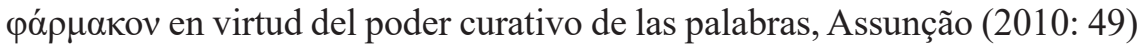
afirma, por el contrario, que tal interpretación "no tiene consistencia alguna en este contexto narrativo concreto, pues es precisamente la tristeza que tal historia puede despertar (sobre todo en Telémaco, el huésped principal) lo

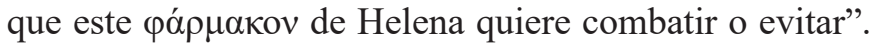

Helena, según su versión de la historia, no dudó en traicionar a los troyanos para cumplir su deseo de regresar a Grecia y volver junto a su hija y su esposo, por quien manifiesta admiración (Od. 4.259-64):

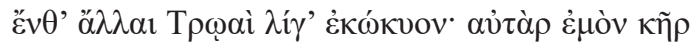

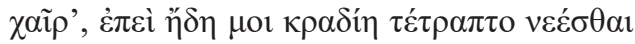

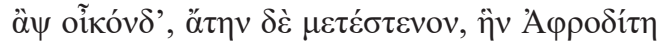

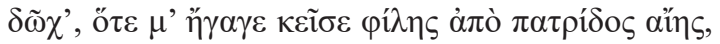

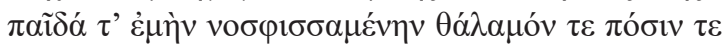

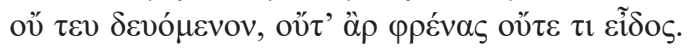

Las troyanas entonces prorrumpieron en fuertes sollozos; mi pecho se llenaba de júbilo, en cambio, pues ya el corazón me impulsaba a volver a mi hogar y deploraba la ofuscación que Afrodita me provocara cuando me condujo alli, lejos de mi tierra patria, tras haber abandonado a mi hija, el tálamo y a un marido que no es inferior a ningún otro hombre ni en inteligencia ni en figura.

Es destacable aquí la mención de Afrodita como responsable de su huida con Paris (261). Doherty afirma, a propósito de estos versos, que en ellos Helena "procura hacer una revisión de su propia historia y promulgar un nuevo $\kappa \lambda \dot{\varepsilon}$ os para sí misma. No obstante, del mismo modo que el canto de las Sirenas se ve contrarrestado por la advertencia de Circe de ofrecerle resistencia, así también le sucede a la historia de Helena a causa de la otra

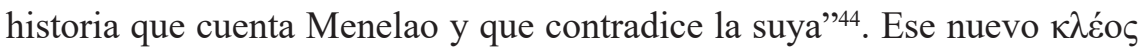

43 Bergren retoma en este trabajo una línea interpretativa ya presente en Plutarco (Quaestiones conviviales 1.1.4, 614c) y Macrobio (Saturnalia 7.1.18).

44 Doherty 1995: 86. Desde una perspectiva distinta, Schein (1995: 25) afirma que, a la luz de las palabras de Penélope en $O d$. 23.218-24, "el final del poema deja abierta y entre 
al que aspiraba Helena queda vinculado, por tanto, al $\kappa \lambda \varepsilon \dot{\delta}$ ऽ de Odiseo. Menelao recuerda la trampa que Helena les quiso tender a los argivos cuando estaban ocultos dentro del caballo de madera: se puso a imitar las voces de sus esposas para hacerles salir, pero Odiseo los detuvo. Menelao atribuye la treta de Helena a algún dios favorable a los troyanos (Od. 4.274-5), pero también añade a continuación (276) que tras ella iba el troyano Deífobo, hecho que, según Christopoulos (2008: 110) podría apuntar a que el engaño de las voces le viniera impuesto a Helena por su nuevo marido.

La crítica siempre ha encontrado problemático cómo conjugar dos relatos yuxtapuestos en los que Helena se presenta como aliada de los griegos, según su propio relato, y como aliada de los troyanos, según el relato de su marido. Ya en la Antigüedad la historia contada por Menelao fue objeto de descrédito y se consideraba que su autoría era distinta de la del relato de Helena. Entre los argumentos esgrimidos estaban la evidente contradicción de esta segunda historia con respecto a la primera, así como la imposibilidad de encontrar una respuesta lógica a cómo podía conocer Helena las voces de las esposas de los aqueos escondidos en el caballo o cómo podían los aqueos pensar que sus esposas se encontraban en Troya (Od. 4.279). A los argumentos en contra de la autenticidad del relato de Menelao se sumaba la inclusión de varios versos $(276 ; 285-9$, todos ellos atetizados por Aristarco) supuestamente interpolados. Un escoliasta de la Odisea ${ }^{45}$ afirmaba que el verso 276 debería suprimirse porque la mención de Deífobo haría alusión al tercer matrimonio de Helena, una invención posterior presente en poemas del Ciclo Épico como la Ilias parva. En opinión de Maniet (1947: 41), no obstante, quienes desde entonces esgrimen este argumento han proyectado precisamente el sentido de tal invención posterior sobre un verso que no menciona explícitamente el hecho de que Défobo sea el marido de Helena. Cuando Menelao pronuncia el verso 276 únicamente le dice a su esposa: "y te seguía Deífobo, semejante

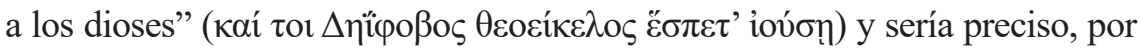
tanto, leer entre líneas la supuesta alusión a la relación matrimonial entre Helena

interrogantes la cuestión de la responsabilidad moral de Helena e incluso del estatus moral del adulterio, a pesar de que el auditorio o lectores se puedan sentir tentados a participar de un juicio mayoritariamente desfavorable contra ella y su comportamiento". La infidelidad de Helena se debió, en opinión de la casta y fiel Penélope, a la acción de un dios que le cegó el entendimiento. Helena habría evitado abandonar su propia casa si hubiese valorado las consecuencias de su elección, pero su mente, obcecada por la divinidad, se dejó seducir por las palabras lisonjeras de Paris.

${ }_{45} \mathrm{H}$ Q en $O d .4 .276$. 
y el troyano. Además, como señala West (1988: 211 ad 276), "si Helena no hubiese sido vigilada por un troyano, no habría habido peligro para los griegos y la precaución adoptada por Odiseo habría sido innecesaria”.

Ya desde la antigüedad se consideraba que los versos 285-9 debían suprimirse porque el personaje de Anticlo no se mencionaba en la Ilíada y procedía del Ciclo Épico. Ahora bien, la atétesis de estos versos "sería claramente perjudicial para el desarrollo literario del relato de Menelao" (Maniet 1947: 44), que en los versos anteriores (266-73) ha ponderado la valentía y la prudencia de Odiseo, creando así en el auditorio la expectativa de un relato que ilustre las virtudes del héroe; por el contrario, si se atetizan los versos 285-9, solo queda el verso 284 como testimonio del coraje y la voluntad inquebrantable de Odiseo, mientras que se suprimen los versos que relatan cómo le tapa la boca a Anticlo "con sus robustas manos" ( $\chi \varepsilon \rho \sigma i ̀ . .$.

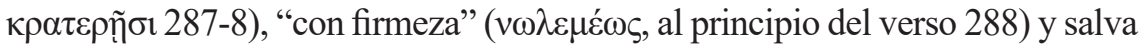
así a todos los griegos que se ocultan con él dentro del caballo de madera.

La controversia moderna con respecto a las dos historias contadas sucesivamente por Helena y Menelao ofrece conclusiones de signo contrario: Beye $^{46}$ sugiere que los relatos contradictorios de la pareja representan su manera de hacer frente a un resentimiento acumulado y que el poeta épico estaría tratando la cuestión de cómo se comportarían ambos tras la guerra de Troya. Austin ${ }^{47}$ los interpreta primero como un ejemplo de

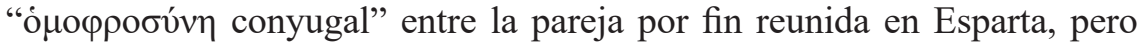
más tarde ${ }^{48}$ corrige tal opinión. Minchin ${ }^{49}$ considera las dos historias "como un gesto colaborativo, como un medio de demostrar comprensión mutua y comunicación", mientras que Winkler ${ }^{50}$ ve aquí "un encantador ejemplo de una pareja mal avenida". Clader ${ }^{51}$, por su parte, considera que el poeta épico podría haber utilizado aquí el material tradicional existente sobre dos versiones distintas acerca de Helena, en una de las cuales es leal a los griegos y, en la otra, a los troyanos. Clader añade que "Homero cuenta las dos versiones sin hacer ningún comentario, pero sitúa a la Helena desleal en segunda posición narrativa, que es una posición más enfática. Al auditorio se le deja creer, naturalmente, que la segunda historia es la más certera y

\footnotetext{
Beye 1966: 173-4.

Austin 1975: 188-9.

Austin 1994: 81-2.

Minchin 2007: 277.

Winkler 1990: 140.

Clader 1976: 35.
}

Humanitas 69 (2017) 9-45 
que Helena es menos creíble que su esposo". Christopoulos ${ }^{52}$ detecta en las dos historias "una comparación subyacente entre Helena y Ulises o, más exactamente, una anulación de la acción de Helena por la acción de Ulises". Por su parte, Olson ${ }^{53}$ distingue tres niveles significativos en los dos relatos contrapuestos: 1) evocan las hazañas de Odiseo en el transcurso de la guerra de Troya ante un acongojado Telémaco que ha venido a Esparta en busca de noticias de su padre; 2) sirven de auto-justificación y de mutua recriminación para sus respectivos narradores, de modo que la tensión entre ambos contribuye a la dialéctica entre los sexos que subyace en el poema; 3) preparan al auditorio para el retorno a Ítaca de Odiseo y para el momento crucial de su reencuentro con Penélope. Boyd ${ }^{54}$ sugiere que contemplemos las dos historias centrando nuestra atención, no en Helena y Menelao, como se ha hecho a menudo, sino en Helena y Odiseo, puesto que este enfoque puede "añadir nuevas facetas a nuestra comprensión (...) de Helena en comparación con otros personajes femeninos de la Odisea y, tal vez lo más importante, del poder real de Helena en la historia de Troya".

Worman advierte acertadamente, en mi opinión, que los lectores modernos hemos exagerado a la hora de interpretar el relato de Menelao como una forma premeditada y exitosa de poner en tela de juicio la historia contada por su esposa. Lo primero que Menelao dice tras haberla escuchado

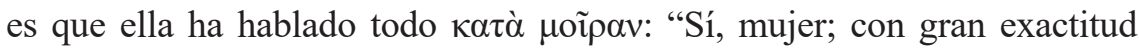

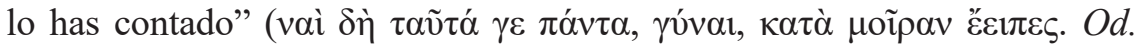
4.266). Si Menelao pretende refutar, a continuación, la historia de Helena, resulta extraño que inicie tal refutación con la afirmación del verso 266,

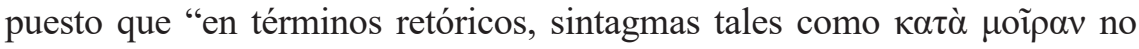
evalúan la veracidad del discurso, sino más bien si el orador se comporta apropiadamente con sus palabras" 55 . La autora apoya sus afirmaciones con el trabajo de Nagy, quien ha argumentado convincentemente que estos sintagmas indican en Homero conformidad con la dicción épica ${ }^{56}$. Por otra

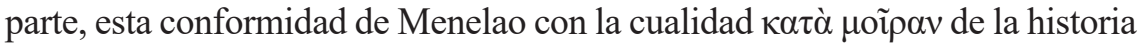
contada por Helena se revela lingüísticamente en su propia historia: así, por ejemplo, repite en el verso 271 la misma frase que pronunció ella en el verso

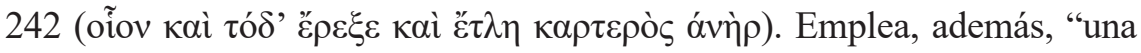

\footnotetext{
Christopoulos 2008: 105.

Olson 1989: 387-94;

Boyd 1998: 2.

Worman 2001: 32-3.

56 Nagy 1979: 40, n.2 y 82, n. 134.
} 
estrategia introductoria similar, señalando su propio estatus y admirando la fortaleza de Odiseo en el servicio prestado a los aqueos (Od. 4.267-73)",57.

Hemos podido constatar hasta aquí la multiplicidad de opiniones que se han ido sumando al estudio de una escena concreta de la Odisea. Yo, por mi parte, opino que la polémica sobre la yuxtaposición del retrato antitético de Helena - partidaria de los griegos en la historia que ella misma cuenta, pero partidaria de los troyanos en la historia que cuenta Menelao-, procede de haber interpretado este episodio aisladamente, es decir, sin contemplar su integración en el conjunto de un poema cuyo protagonista es el héroe Odiseo y su historia particular desde que abandonó Troya para regresar a Ítaca. Coincido con varios de los autores que he citado anteriormente cuando señalan el carácter ancilar del retrato contradictorio de Helena en el canto 4, puesto que, en mi opinión, las dos historias contadas sucesivamente por Helena y Menelao están al servicio de la glorificación de Odiseo. Aunque Helena se atribuya a sí misma de manera enfática la clarividencia de haber sido la única que descubre la identidad del héroe bajo su disfraz de mendigo (...oi

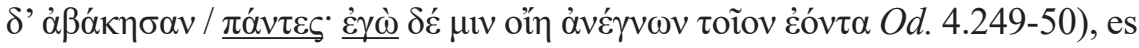
precisamente ella la que ensalza la valentía y la astucia de Odiseo en la mayor parte de los versos que componen su relato: por su gran número, no podría

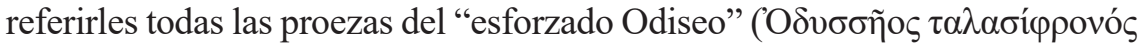

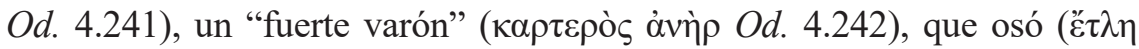
$O d .4 .242$ ) infiltrarse en Troya y nadie le reconoció disfrazado de mendigo, "tras haberse infligido a sí mismo vergonzosas heridas y haberse cubierto los

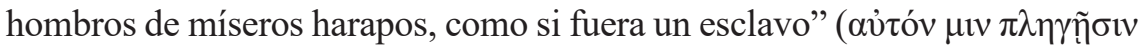

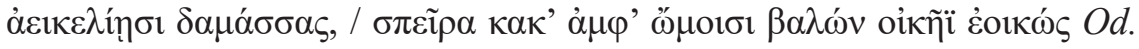
4.244-5). Es destacable este detallismo con el que Helena subraya la gran capacidad del héroe para el engaño, mientras que solo dedica el verso 250, anteriormente citado, a señalar su propia capacidad para descubrir quién se

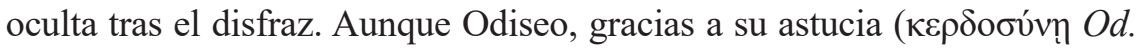
4.251), consigue esquivar las preguntas de Helena, finalmente le cuenta todos

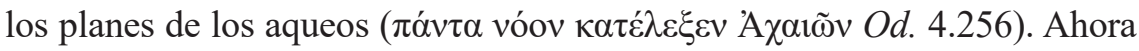
bien, la revelación de Odiseo solo tiene lugar después de que ella misma lo baña, lo perfuma, le ofrece ropa nueva y le promete con firme juramento

57 Worman 2001: 33 y esp. n. 47, donde la autora compara los pasajes 4.236-43 y 267-73 pronunciados, respectivamente, por Helena y Menelao. Tanto una como otro comienzan afirmando su sabiduría y experiencia como narradores para pasar luego a la exaltación del héroe Odiseo. 


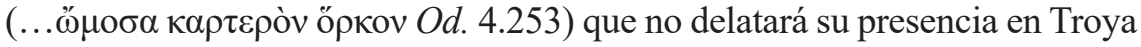
hasta que regrese al campamento aqueo. Helena pondera aquí la prudencia del héroe, que se resiste a desvelar su identidad y se asegura previamente antes de hacerlo. El relato de la esposa de Menelao la retrata también a ella, sin duda alguna, como una mujer astuta y clarividente. Dicha caracterización, no obstante, está supeditada a la de Odiseo.

La condición ancilar del retrato de Helena es todavía más evidente en el relato de Menelao. La imitación que ella hace de las voces de las esposas de los guerreros escondidos dentro del caballo (Od. 4.279; Menelao menciona en un único verso esta peculiar habilidad de su esposa) pone a prueba y demuestra la paciencia, el autocontrol y la determinación firme e inquebrantable del astuto Odiseo, que consigue salvar a sus compañeros -incluido el propio Menelao- impidiéndoles que salgan del caballo o que respondan a la voz de Helena. West ${ }^{58}$ señala que no existe constancia de que el verso 279 fuese atetizado por Aristarco, pero los escolios enfatizan su absurdidad de tal modo que sería posible conjeturar que sí lo hizo. Quienes consideren que el verso debería suprimirse no pensarían así si examinasen su integración dentro del diseño global de un poema en el que abunda lo sobrenatural, lo fantástico y lo irracional. En su azaroso viaje de regreso a Ítaca, Odiseo y sus compañeros se aventuran en un mundo poblado por gigantes, brujas, sirenas y monstruos marinos; en el canto 10, el propio héroe recibe de manos de Eolo un odre lleno de vientos favorables para la navegación y en el canto 11 desciende al Hades, donde habla con su difunta madre Anticlea, con Elpénor, compañero fallecido en la mansión de Circe, con el adivino Tiresias y con el rey Agamenón, que le informa de que fue asesinado por Egisto y Clitemnestra. Dentro de un poema épico cuyas situaciones y personajes a menudo son inexplicables desde el realismo psicológico, ¿por qué hemos de cuestionar la autenticidad de un verso en el que Helena, la hija de Zeus ${ }^{59}$, se muestra dotada de la capacidad de imitar otras voces con tal grado de virtuosismo que los guerreros aqueos creen estar oyendo a sus propias esposas?

En los dos párrafos anteriores he querido subrayar la idea de que la caracterización de Helena en el canto 4 no debe ser valorada per se, sino

58 West 1988: 211.

59 En este canto hay tres menciones explícitas de la paternidad de Zeus ('E $\lambda \varepsilon ́ v \eta$,

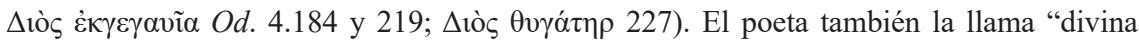

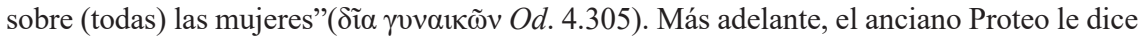

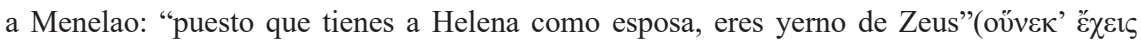

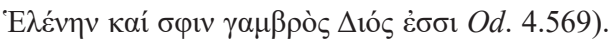


que la debemos contemplar dentro de un propósito compositivo más amplio en el que el retrato contradictorio de la esposa de Menelao no constituye un fin en sí mismo, sino un medio para poner en primer término las cualidades heroicas de Odiseo. Aunque West ${ }^{60}$ advierte que debemos evitar leer entre líneas en busca de sutilezas psicológicas ajenas al propósito del poeta, no obstante esta autora opina que "la yuxtaposición de estas dos historias complementarias sugiere la labilidad del carácter de Helena y una bastante vanidosa complacencia en secretos peligrosos". También opina que "revela las tensiones inherentes en la aparentemente plácida relación de Helena con Menelao" ${ }^{61}$ y afirma que "ella [Helena] habría hecho mejor en resistir la tentación de evocar su pasado en Troya" y que "su iniciativa sirve de estímulo a su esposo para revelar a los jóvenes a los que intenta impresionar un incidente que la hace sentir avergonzada". Ahora bien, yo me pregunto, ¿en qué versos señala el poeta esa "vanidosa complacencia" o ese sentimiento de vergüenza experimentado por Helena? ¿Quiere Helena "impresionar" a Telémaco y Pisístrato? Con respecto a la historia de la imitación de las voces contada por Menelao, West ${ }^{62}$ afirma que "su [de Helena] comportamiento no sugiere una traición deliberada; si hubiese cambiado de opinión desde su encuentro con Odiseo, podía haber destruido a los griegos ocultos en el caballo con bastante facilidad sin necesidad de ir hasta allí. (...) Nos quedamos con la impresión de una mujer consentida, aburrida, ansiosa de emociones y de sensación de poder”. ¿Cómo ha llegado West a semejantes conclusiones partiendo de un texto significativamente parco y austero en la descripción psicológica de los personajes? ${ }^{63}$.

De acuerdo con las reflexiones anteriores, opino que la contraposición entre las dos historias contadas por la pareja espartana no constituye meramente un deliberado recurso de caracterización supuestamente orientado a que el poeta épico ponga de manifiesto la ambigüedad de Helena. Dicha contraposición encaja dentro de un patrón de dualidades que recorre los primeros trescientos cinco versos del canto 4 . En cuanto a su estructuración,

60 West 1988: 208-9.

${ }^{61}$ El trabajo de Schmiel (1972) está orientado, precisamente, a señalar en el conjunto del canto IV la discordia interna latente en Esparta.

62 West 1988: 210-11.

63 Mucho antes que en West, con respecto a la imitación de las voces, también podemos leer en Maniet (1947: 45): "me parece que la actitud de Helena es de atolondramiento, causado por su deseo de volver a ver y a escuchar a sus amigos". Maniet incluso considera "ampliamente justificada por el sentido común"(42) la atétesis del verso 279. 
podemos distinguir una primera parte (Od. 4.1-218), dominada por Menelao, y una segunda parte (Od. 4.219-305), dominada por Helena. El canto comienza con la celebración de las bodas de Hermíone y Megapentes, pero la boda de la hija de Helena tendrá lugar en el hogar de Aquiles, mientras que la del hijo que tuvo Menelao con una esclava se celebrará en Esparta ${ }^{64}$. Telémaco y Pisístrato llegan al palacio en calidad de $\xi \dot{\varepsilon} v o r$ de Menelao y Helena. La alegría del banquete se transforma en llanto cuando Menelao evoca ante Telémaco el recuerdo de Odiseo. La admiración del joven ante la fastuosidad del palacio y la riqueza de Menelao contrasta con el sentimiento de pérdida y dolor que experimenta el rey espartano al acordarse de los compañeros muertos por su causa en Troya y, especialmente, al acordarse de Odiseo (Od. 4.97-116) ${ }^{65}$. En la historia que cuenta Helena ella "presenta a Odiseo como el personaje activo y a sí misma como personaje pasivo; su rol, en pocas palabras, consiste en mantener la boca cerrada (...) Menelao precisamente invierte los roles. Su historia empieza con una Helena que actúa; ahora el papel de los griegos consiste en guardar silencio (...). En su propia historia Helena actúa entre bambalinas, discretamente, en privado; en la historia de Menelao ella da pasos al frente y se sitúa en el centro - $\mathrm{y}$ da tres vueltas en torno al caballo- con Deífobo a la zaga" ${ }^{\prime 66}$.

El patrón de dualidades que he detectado en el canto 4 de la Odisea es igualmente extensivo al plan general del poema, puesto que no solo es posible establecer la polaridad entre la pareja formada por Helena y Menelao, por un lado, y Penélope y Odiseo, por otro. También es posible constatar a lo largo del poema el paralelismo y el contraste entre el grupo constituido por Agamenón, Clitemnestra, Egisto y Orestes, por un lado, y el constituido por Odiseo, Penélope, los pretendientes y Telémaco, por otro. A propósito de estos personajes, Heubeck ${ }^{67}$ observa que "la semejanza en las situaciones y los roles es significativa, pero la solución final ofrece el

64 Tanto Schmiel (1972: 464-5) como West (1988: 201) señalan la extrañeza de este hecho. En opinión de Assunção (2010: 41, n.10), si la única boda que se está celebrando es la de Megapentes, la ausencia de Helena al comienzo del canto IV bien podría explicarse a causa de la ausencia de su hija Hermíone. Así se comprendería mejor también la repentina entrada de Helena en el verso 121, que viene de su aposento y parece no haber participado, por tanto, de la celebración.

65 Para un estudio más detallado de estas polaridades, véase el trabajo de Bergren (2008: 111-30).

66 Schmiel 1972: 468-9

67 Heubeck 1988: 17. 
máximo contraste. Agamenón fue uno de los primeros en volver al hogar; Odiseo fue el último. Contra el trasfondo del vergonzoso fin de Agamenón a manos de la esposa infiel y de su malvado rival, se destaca el feliz destino de Odiseo con todo detalle. La leal espera de Penélope en medio de una situación que parece desesperada, su resistencia ante los pretendientes y su sensatez le han evitado [a Odiseo] el destino de Agamenón y, en último término, le han proporcionado el cumplimiento de sus anhelos".

Este breve estudio sobre el papel de Helena en la Odisea permite constatar, como anteriormente en la Ilíada, que la ambigüedad del personaje en ambos poemas se debe a factores de forma y fondo que van más allá de una deliberada caracterización contradictoria ideada supuestamente por el poeta épico. Antes bien, la caracterización de Helena está al servicio de un proyecto compositivo en el que no es pertinente determinar cómo es ella, sino por qué el poeta le asigna unos rasgos cuya ambigüedad no se justifica per se, porque tales rasgos se ajustan al diseño compositivo global del poema, no al revés. Por otra parte, la responsabilidad de Helena en la guerra de Troya, que en la Ilíada se diluye en una suma de responsabilidades irreductibles a las acciones de una sola mujer, aparece sustituida en la Odisea por la presentación de su relación particular con Menelao tras el regreso de ambos a Esparta.

\section{BIBLIOGRAFÍA}

Alexiou, M. (2002), The Ritual Lament in Greek Tradition. Lanham: Rowman \& Littlefield Publishers, Inc.

Assunção, T. R. (2010), "Luto e banquete no Canto IV da Odisseia (97-226)", Letras Clássicas (USP) 14: 34-50.

Austin, N. (1994), Helen of Troy and Her Shameless Phantom. Ithaca \& London: Cornell University Press.

Bergren, A. (2008), "Helen's 'good drug"”. Weaving Truth - Essays on Language and the Female in Greek Thought. Cambridge, Mass.: Harvard University Press: 111-30.

Bettini, M. \& Brillante, C. (2008) El mito de Helena. Imágenes y relatos de Grecia a nuestros dias. Madrid: Akal.

Beye, C. R. (1966), The Iliad, the Odyssey, and the Epic Tradition. Garden City, N. Y.: Doubleday Anchor Books.

Boyd, T. W. (1998), “Recognizing Helen”, ICS 23: 1-18. 
Christopoulos, M. (2008), “Quelques Remarques sur Hélène dans 1' Odyssée. À la Recherche des Innovations Mythographiques et Narratives”, Gaia 11: 101-20.

Clader, L. L. (1976), Helen. The Evolution from Divine to Heroic in Greek Epic Tradition. Mnemosyne 42. Leiden: Brill.

Collins, L. (1988), Studies in Characterization in the Iliad. Frankfurt: Athenäum Monografien. Altertumswissenschaft.

Conti Jiménez, L. (1999), “La Expresión de la Causa en Homero con Referentes Humanos", Emerita 67.2: 295-313.

Doherty, L. E. (1995), "Sirens, Muses and Female Narrators in the Odyssey", in B. Cohen (ed.) The Distaff Side. Representing the Female in Homer's Odyssey. New York, Oxford: Oxford University Press, 81-92.

García Gual, C. (ed.) (1999), Ilíada. Odisea. Edición bilingüe. Madrid: Espasa Calpe. Graver, M. (1995), “Dog Helen and Homeric Insult”, ClAnt, 14.1: 41-61.

Gumpert, M. (2001), Grafting Helen. The Abduction of the Classical Past. Wisconsin: University of Wisconsin Press.

Heubeck, A. (1988), “General Introduction”. in A. Heubeck, S. West, J. Hainsworth, (eds.) A Commentary on Homer's Odyssey vol. I, Introduction and Books i-viii. Oxford: Oxford University Press, 3-23.

Hirvonen, K. (1968), Matriarchal Survivals and Certain Trends in Homer's Female Characters. Helsinki: Suomalainen Tiedeakatemia.

Hooker, J. T. (1979), Homer. Iliad III. Bristol: Bristol Classical Press.

Kennedy, G. A. (1986), “Helen's Web Unraveled”, Arethusa 19: 5-14.

Kirk, G. S. (1987), The Iliad: A Commentary. Cambridge: Cambridge University Press.

Komornicka, A. M. (1991), "Hélène de Troie et son Doublé dans la Littérature Grecque (Homère et Euripide)", Euphrosyne 19: 9-26.

López Gregoris, R. (1996), "El Matrimonio de Helena: Solución Lexemática", Epos 12: 15-30.

Lynn-George, M. (1988), Epos: Word, Narrative and the Iliad. Basingstoke: Macmillan.

Martin, R. (1989), The Language of Heroes: Speech and Performance in the Iliad. Ithaca: Cornell University Press.

Maniet, A. (1947), "Pseudo-interpolations et scènes de ménage dans l'Odyssée", $A C$ 16.1: 37-46.

Minchin, E. (2007), Homeric voices: Discourse, memory, gender. Oxford: Oxford University Press.

Monsacré, H. (1984), Les Larmes d'Achille: le Héros, la Femme et la Souffrance dans la Poésie d'Homère. Paris: Albin Michel. 
Nagy, G. (1979), The Best of the Achaeans. Baltimore: The Johns Hopkins University Press.

Olson, S. D. (1989), "The Stories of Helen and Menelaus (Odyssey 4.240-89) and the Return of Odysseus", AJPh 110: 387-94.

Pantelia, M. C. (2002), "Helen and the Last Song for Hector”, TAPhA 132: 21-7.

Perceau, S. (2011), “«Mais Devançant Ménélas, Hélène...» (Od. XV, 172). Hélène et Ménélas au Chant IV de 1' Odyssée”, Gaia 14: 135-53.

Reckford, K. J. (1964), "Helen in the Iliad”, GRBS 5: 5-20.

Roisman, H. M. (2006), "Helen in the Iliad; Causa Belli and Victim of War: From Silent Weaver to Public Speaker", AJPh 127: 1-36.

Ruiz de Elvira, A. (1974), “Helena. Mito y Etopeya”, $C F C(G)$ 6: 95-133.

Ryan, G. J. (1965), “Helen in Homer”, CJ 61: 115-7.

Schein, S. L. (1995), "Female Representations and Interpreting the Odyssey", in B. Cohen (ed.) The Distaff Side. Representing the Female in Homer's Odyssey. New York, Oxford: Oxford University Press, 17-27.

Silk, M. S. (1987), Homer. The Iliad. Cambridge: Cambridge University Press.

Schmiel, R. (1972), “Telemachus in Sparta”, TAPhA 103: 463-72.

Taplin, O. (1992), Homeric Soundings: The Shaping of the Iliad. Oxford: Clarendon Press.

Vivante, P. (1985), Homer. New Haven, Conn.: Yale University Press.

West, S. (1988), "Books I-IV”, in A. Heubeck, S. West, J. Hainsworth (eds.) A Commentary on Homer's Odyssey vol. I, Introduction and Books i-viii. Oxford: Oxford University Press, 49-245.

Willcock, M. M. (1978), The Iliad of Homer: Books I-XII. Houndsmills: Macmillan Education. Rpt. New York: St. Martin's Press.

Winkler, J. J. (1990) The Constraints of Desire: The Anthropology of Sex and Gender in Ancient Greece. New York \& London: Routledge.

Worman, N. (2001), “This Voice Which Is Not One: Helen's Verbal Guises in Homeric Epic”. En A. Lardinois \& L. McClure (eds.), Making Silence Speak. Women's Voices in Greek Literature and Society. Princeton, New Jersey: Princeton University Press. 19-37.

Zanker, G. (1994), The Heart of Achilles: Characterization and Personal Ethics in the Iliad. Michigan: University of Michigan Press. 